\title{
Tuning the processability, morphology and biodegradability of clay incorporated PLA/LLDPE blends via selective localization of nanoclay induced by melt mixing sequence
}

\author{
L. As 'habi ${ }^{1}$, S. H. Jafari ${ }^{1}$, H. A. Khonakdar ${ }^{2}$, R. Boldt ${ }^{3}$, U. Wagenknecht ${ }^{3}$, G. Heinrich ${ }^{3}$ \\ ${ }^{1}$ School of Chemical Engineering, College of Engineering, University of Tehran, 11155-4563, Tehran, Iran \\ ${ }^{2}$ Iran Polymer and Petrochemical Institute, 14965-115, Tehran, Iran \\ ${ }^{3}$ Leibniz Institute of Polymer Research Dresden, Hohe Str. 6, D-01069, Dresden, Germany
}

Received 14 May 2012; accepted in revised form 8 August 2012

\begin{abstract}
Polylactic acid (PLA)/linear low density polyethylene (LLDPE) blend nanocomposites based on two different commercial-grade nanoclays, Cloisite ${ }^{\circledR} 30 \mathrm{~B}$ and Cloisite ${ }^{\circledR} 15 \mathrm{~A}$, were produced via different melt mixing procedures in a counter-rotating twin screw extruder. The effects of mixing sequence and clay type on morphological and rheological behaviors as well as degradation properties of the blends were investigated. The X-ray diffraction (XRD) results showed that generally the level of exfoliation in 30B based nanocomposites was better than $15 \mathrm{~A}$ based nanocomposites. In addition, due to difference in hydrophilicity and kind of modifiers in these two clays, the effect of $30 \mathrm{~B}$ on refinement of dispersed phase and enhancement of biodegradability of PLA/LLDPE blend was much more remarkable than that of 15A nanoclay. Unlike the one step mixing process, preparation of nanocomposites via a two steps mixing process improved the morphology. Based on the XRD and TEM (transmission electron microscopic) results, it is found that the mixing sequence has a remarkable influence on dispersion and localization of the major part of 30B nanoclay in the PLA matrix. Owing to the induced selective localization of nanoclays in PLA phase, the nanocomposites prepared through a two steps mixing sequence exhibited extraordinary biodegradability, refiner morphology and better melt elasticity.
\end{abstract}

Keywords: biodegradable polymers, mixing methods, polylactic acid, nanocomposites

\section{Introduction}

In recent years, environmental pollution has become a great concern due to the high impact of plastic wastes in daily use. To cope with this problem, the commodity synthetic polymers can be replaced with the biodegradable polymers which are susceptible to microbial action. The most popular and biodegradable polymers are aliphatic polyesters, such as polylactic acid (PLA), polycaprolactone (PCL), poly (butylene adipate-co-terephthalate) (PBAT) and polyhydroxybutyrate (PHB). Amongst the biodegradable polymers, PLA has a number of interesting properties including biodegradability, good mechanical properties, and processability. For these reasons PLA is an interesting candidate for producing commercial biodegradable materials. However, high brittleness and cost of PLA are two major obstacles for commercialization and many applications [1-3].

Oyama showed that reactive blending of PLA with EGMA poly (ethylene-glycidyl methacrylate) improves the elongation at break of PLA. These improvements in mechanical properties were achieved without sacrificing the heat resistance of PLA. It was deduced that crystallization of the PLA matrix plays a significant role in toughening [4].

\footnotetext{
*Corresponding author, e-mail: shjafari@ut.ac.ir (C) BME-PT
} 
Preparation of blends, conventional composites and nanocomposites using inorganic fillers or nanofillers are among the routes to improve some of the properties of PLA and reducing the production cost. Thermal stability, gas barrier properties, strength, low melt viscosity, are among the properties that can be improved by these multiphase systems [5]. The nanocomposite technology is a beneficial route for improving biodegradability and processability of these blends.

Amongst the petrochemical-based polymers, polyethylene (PE) is one of the most consumed polymers especially in the packaging industry. This polymer can degrade under oxygen and ultra violet radiation however, the degradation rate of $\mathrm{PE}$ after disposal is very slow. Therefore a blend nanocomposite of PLA and linear low-density polyethylene (LLDPE) may be a suitable choice for excellent biodegradable material.

According to the American Society for Testing and Materials (ASTM), a biodegradable plastic is a plastic that degrades because of the action of naturally occurring microorganisms such as bacteria, fungi, and algae. There is a difference between a biodegradable and a compostable plastic. A compostable plastic is a plastic that undergoes degradation by biological processes during composting to yield carbon dioxide, water, inorganic compounds, and biomass at a rate consistent with other known compostable materials and leaves no visually distinguishable or toxic residues. Therefore, all compostable plastics are biodegradable, but the reverse is not true. A major problem with PLA matrix is the slow rate of degradation as compared to the rate of waste accumulation. Often, an unfavorable hydrolytic degradation rate will limit the PLA applications compared to the other biodegradable polymers. Considerable efforts have been made to control and accelerate the hydrolytic degradation rate. Despite the considerable number of reports concerning the enzymatic degradation of PLA [6-8] and various PLA blends [9], the compost degradability of PLA and its blend with conventional petrochemical-based polymers are still very little known. Very limited researches on degradation behavior of PLA/PE exist in the literatures [10-12] till date. Singh and coworkers studied the degradation behavior of LLDPE/ PLA blend [10]. They pointed out that the blend of LLDPE/PLA (80wt\% LLDPE and 20\% PLA) degrades faster than pure LLDPE. They also found that the mechanical properties of this system depend on the blending ratios and the compatibilizer content [11].

PLA/PE blends have also attracted a huge interest because it complements brittleness of the PLA. Studies have shown that blending of PLA with LLDPE resulted in a significant increase in PLA ductility and toughness on expense of strength and modulus [13-17]. Anderson and coworkers [13] showed that for the amorphous PLA the toughening was achieved only when a poly (L-lactide) (PLLA)PE block copolymer was used as compatibilizer. On the other hand Kim and coworkers investigated blends of PLLA and low-density polyethylene (LDPE) and found that the domain size of dispersed phase decreased and the tensile properties enhanced significantly by using a reactive compatibilizer having glycidyl methacrylate (GMA) functional group [14]. Because of the immiscibility of this system, several researchers employed different compatibilizers to further tailoring the properties [16-17]. Rezgui et al. [16] studied the plastic deformation and modeled the creep behavior of LDPE reinforced with PLA. They pointed out that the deformation damage of LDPE/PLA blends increased with increasing PLA content. They also found that with increasing concentrations of PLA, the blend showed higher Young's modulus, stiffer viscoelastic response and earlier fracture [17].

PLA/clay nanocomposites have already been extensively studied in terms of mechanical, thermal, fire retardancy and crystallization behavior. However, to date there have been very limited reports on the tuning of PLA/LLDPE properties especially biodegradability by addition of nanoparticles and developing the PLA/LLDPE blend nanocomposites. Recently Nuñez and coworkers studied the PLA/ LLDPE nanocomposites based on sepiolite [18]. They showed that the compatibilized blends prepared without clay have higher thermal degradation susceptibility and tensile toughness than those prepared with sepiolite and significant changes in complex viscosity and melt elasticity values were observed. This blend nanocomposites exhibited similar thermal degradation, lower tensile strength, and Young's modulus and increased elongation at break and tensile toughness, complex viscosity, and storage modulus compared with the nanocomposite of PLA. 
However, the most crucial factor in enhancement of properties in nanocomposites is the extent of interaction between nanoclay and polymer matrix which leads to the selective localization of nanoclay in multiphase systems. In this context addition of compatibilizer to a clay-containing multiphase system can have its own contribution towards clay positioning and its state of dispersion due to induced changes in the system thermodynamic. This topic has been discussed intensively in the literature [1929]. Undoubtedly, the mixing procedure has also a strong effect on the localization of nanoclay. The simplest and most widely reported mixing procedure is the simultaneous feeding of all components in to the mixer. A second alternative is first to incorporate the nanoclay into a polymer having the higher affinity and then adding the rest of components. Depending on these mixing sequences, the nanoclay may migrate from one phase to the other to reach its equilibrium distribution which involves particle displacement inside the blend [19]. This phenomenon has been discussed in the case of different nanocomposites hybrid [20-24]. Elias et al. [21] studied polypropylene (PP)/polystyrene (PS)/ silica blend and the effect of the sequence of addition where the silica was first mixed with PP and the obtained composite was then mixed with PS. They observed that all the hydrophilic silica moves from the PP with which it has lower affinity towards the PS preferred phase. In a series of reports Gubbels et al. [21-23] introduced carbon black in polystyrene/ polyethylene system to obtain electrical conductivity. They clearly illustrated some of the influential factors on the distribution of nanofillers and their effects on the material properties. Zaikin et al. [24] have varied the sequence of mixing for carbon black filled polymer blends and found enhanced conductivity when the filler had to cross the interface.

In this study the compatibilized blend nanocomposites of PLA and LLDPE were prepared. LLDPE was chosen as a counterpart of PLA due to its superior mechanical properties, low price and major use for packaging. A terpolymer (EBAGMA) of ethylene, butylacrylate (BA) and glycidylmethacrylate (GMA) was selected as a compatibilizer for the PLA/ LLDPE system. The chemical groups of this compatibilizer are similar to poly (ethylene-glycidyl methacrylate) which was used by Oyama [4] as a reactive component for improving the brittleness of PLA. The aim of our work is to improve the brittle- ness of PLA with a suitable composition of the most consumed polymer (LLDPE) with keeping its high modulus, and its biodegradability. For this reason the blend composition of 75/25 was selected.

Considering the importance of PLA/LLDPE system from the environmental viewpoints and the influential role of nanoclay on biodegradability, morphology and processability of the system and also in view of the very limited research on this particular system the current work is aimed to explore the influence of mixing procedure as one of the most influential kinetic parameters on localization of nanoclay and its effects on processability, biodegradability and morphology of compatibilized PLA/ LLDPE/clay system.

\section{Experimental}

\subsection{Materials and samples preparation}

Polylactide (4042D) used in this study was a commercial product of NatureWorks (USA). The ratio of $\mathrm{L}$ and $\mathrm{D}$ isomeric forms in this grade of PLA is about 96/4. The linear low density polyethylene (LLDPE) used was also a commercial grade (LL 4004EL) supplied by ExxonMobile Chemical (USA), having a melt flow index of $3.6 \mathrm{~g} / 10 \mathrm{~min}\left(190^{\circ} \mathrm{C}\right.$, $2.16 \mathrm{~kg}$ ). The Elvaloy ${ }^{\circledR}$ PTW (EBAGMA) which is a terpolymer of ethylene, butylacrylate (BA) and glycidylmethacrylate (GMA) with MFI of $12 \mathrm{~g} / 10 \mathrm{~min}$ $\left(190^{\circ} \mathrm{C}, 2.16 \mathrm{~kg}\right)$ supplied by DuPont (USA) was used as a reactive compatibilizer. Two different commercial nanoclays (Southern Clay Products, Inc.), Cloisite ${ }^{\circledR}$ 30B (30B), MMT-Na ${ }^{+}$modified with bis-(2-hydroxyethyl) methyl tallow alkyl ammonium cations and Cloisite ${ }^{\circledR} 15 \mathrm{~A}(15 \mathrm{~A}), \mathrm{MMT}^{-\mathrm{Na}^{+}}$ modified with dimethyl, dehydrogenated tallow, quaternary ammonium cations were used. The chemical structures of modifiers are showed in Figure 1. Before mixing, all the polymers and the nanoclays were dried in a vacuum oven at $50^{\circ} \mathrm{C}$ for $24 \mathrm{~h}$. A counter-rotating twin-extruder (ZSK 30) equipped with gravimetric feeders and a strand pelletizer, were employed to compound the hybrids. In order to investigate the effect of mixing methods, the nano-

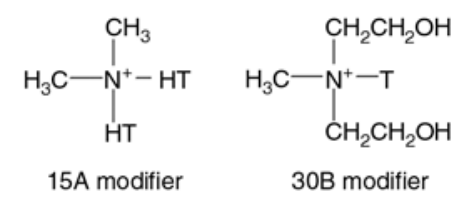

Figure 1. Structure of Cloisite 30B and Cloisite 15A modifiers 
composites were prepared in two ways. In one step mixing procedure, all the components were added to the extruder all together. In the other method all the nanocomposites were prepared in a two steps mixing procedure in which the nanoclay was precompounded with the polymer having the higher affinity followed by the addition of the obtained material to the second polymer during a second extrusion step. In other words, in the $30 \mathrm{~B}$ based nanocomposites due to the better affinity of the $30 \mathrm{~B}$ modifier with PLA, 30B nanoclay was first mixed with PLA and the resulting composite was then mixed with LLDPE and compatibilizer. In the 15A based nanocomposites, 15A nanoclay was first mixed with LLDPE and this composite was then mixed with PLA and compatibilizer. A screw speed of $150 \mathrm{rpm}$ and a feed rate of $10 \mathrm{~kg} / \mathrm{h}$ were used for all runs. The extrusion temperature profile was set from 160 to $190^{\circ} \mathrm{C}$ from hopper to die. The blend and nanocomposite pellets were then dried in a vacuum oven at $50^{\circ} \mathrm{C}$ for $24 \mathrm{~h}$ prior for characterization. The PLA/LLDPE blend compositions were $75 / 25$. The compatibilized blend and nanocomposites had about $5 \mathrm{wt} \%$ compatibilizer. The nanoclay loading in each nanocomposite samples was about 3, 4.5 and $6 \mathrm{wt} \%$ of the total mixture. The nanoclay content and its type are indicated by a number and a letter in the sample name (e.g., 3\% 30B it means $3 \mathrm{wt} \%$ Cloisite 30B).

\subsection{Characterization}

Wide Angle X-Ray Scattering (WAXS) analyses were performed on injection molded specimens with XRD 3003 (Seifert-FPM Freiberg/Sa, Germany) using $\mathrm{Cu}-\mathrm{K}_{\alpha} \mathrm{X}$-ray source. Since WAXS is sensitive to any orientation in the sample, therefore the injection molded samples with lower orientation than that of the extruded samples were used for the WAXS measurements. The continuous scanning angle range used in this study was from 1 to $10^{\circ}$ at $40 \mathrm{kV}$ and $30 \mathrm{~mA}$. The scanning rate was $1 \% \mathrm{~min}$ with a step size of $0.05^{\circ}$. Standard tensile test samples (ISO 527-1) were prepared by injection molding operated at 175 to $205^{\circ} \mathrm{C}$ from hopper to die with the back pressure of 2 bars.

The dispersion of the nanoclay platelets in the blend was studied by means of a transmission electron microscopy (TEM). The samples were cryo-ultramicrotomed from extruded strands in thin section (approximately $40 \mathrm{~nm}$ thick) at $-180^{\circ} \mathrm{C}$ with a dia- mond knife. The sections were observed by means of a Carl Zeiss LIBRA ${ }^{\circledR} 200$ MC, Germany, using an accelerated voltage of $200 \mathrm{kV}$.

Scanning electron microscopy (SEM) was used to characterize the morphology of the blends and nanocomposites. An extruded polymer strand was immersed in liquid nitrogen for some time and a brittle fracture was performed. All specimens after proper drying were sputter coated with $3 \mathrm{~nm} P t$ prior to examination and observed under a NEON 40 EsB (Carl Zeiss, Oberkochen, Germany).

Biodegradability was studied on a homemade compost instrument at $(58+2)^{\circ} \mathrm{C}$. The organic compost, with a $\mathrm{C} / \mathrm{N}$ ratio of $8.7 / 1$, was supplied by Dandy's Top soil Co. (UK). Biodegradation was monitored in every 7 days for a period of approximately 5 months by measuring the residual mass and carbon dioxide $\left(\mathrm{CO}_{2}\right)$ evolution according to the ASTM 5338, 2003. The buried samples were recovered, washed with distilled water, and dried at room temperature before being weighed. Test specimens were prepared by compression molding with a thickness of $1 \mathrm{~mm}$. The shape of the original test samples was $3 \times 3 \times 0.1 \mathrm{~cm}^{3}$. The average values of two measurements were reported. The samples were prepared by compression molding (Paul-otto Weber, Germany) at $205^{\circ} \mathrm{C}$ for 6 minutes preheating and one minute holding at $100 \mathrm{kN}$. The samples were then cooled to $70^{\circ} \mathrm{C}$ using circulating water, after which they were directly cooled to room temperature.

The basic rheological measurements in the melt state were carried out by means of an ARES rotational rheometer, Rheometric Scientific, Inc., USA, using small amplitude oscillatory frequency sweeps and temperature sweeps. The selected geometry for frequency sweeps and heating/cooling sweeps in the molten state was the parallel plate geometry (gap of about $2 \mathrm{~mm}$, and diameter of $25 \mathrm{~mm}$ ). The rheological measurements were performed on compression molded disks obtained under the same compression molding conditions described before.

\section{Results and discussion}

\subsection{WAXS}

The type of filler dispersion in the polymer matrix was determined by WAXS. This technique allows the determination of the spaces between structural layers of the silicate utilizing Bragg's law: $\sin \Theta=$ $n \lambda / 2 d$, where $\lambda$ corresponds to the wave length of the $\mathrm{X}$-ray radiation used in the diffraction experi- 
ment, $d$ the spacing between diffracting lattice planes and $\Theta$ is the measured diffraction angle.

Figure 2 shows the X-ray diffraction (XRD) patterns of the organoclays and the nanocomposites of compatibilized PLA/LLDPE systems. As it is seen from Figure 2, all the hybrids, namely PLA/LLDPE/ 30B and PLA/LLDPE/15A, show the X-ray diffraction peaks characteristic of unexfoliated structures at different clay contents. The XRD patterns were analyzed and the data corresponding to the gallery spacings $\left(\mathrm{d}_{001}\right)$ are presented in Table 1 .

As indicated in Figure 2a, the neat Cloisite 30B shows the (001) diffraction at $2 \Theta=4.75^{\circ}$. This peak corresponds to an interlayer spacing of $18.6 \AA$. The characteristic $\left(\mathrm{d}_{001}\right)$ of $30 \mathrm{~B}$ for PLA/LLDPE/30B nanocomposites shifted to the $2 \Theta=2.6^{\circ}$ corresponding to a d-spacing of $34 \AA$, which indicates that some PLA molecular chains were intercalated between the organoclay galleries, forming an inter-

Table 1. XRD data for pristine organoclays and PLA/LLDPE blend nanocomposites

\begin{tabular}{|l|c|c|c|c|}
\hline \multicolumn{1}{|c|}{ Samples } & \multicolumn{2}{c|}{$\mathbf{d}_{\mathbf{0 0 1}}[\AA]$} & \multicolumn{2}{c|}{$\mathbf{2 \Theta}\left[{ }^{\circ}\right]$} \\
\hline Cloisite 30B (30B) & \multicolumn{2}{|c|}{18.6} & \multicolumn{2}{c|}{4.75} \\
\hline Cloisite 15A (15A) & \multicolumn{2}{|c|}{34.6} & \multicolumn{2}{c|}{2.55} \\
\hline & \multicolumn{2}{|c|}{ One step mixing } & Two steps mixing \\
\cline { 2 - 6 } $\mathbf{d}_{\mathbf{0 0 1}}[\AA \boldsymbol{\AA}]$ & $\mathbf{2 \Theta}\left[{ }^{\circ}\right]$ & $\mathbf{d}_{\mathbf{0 0 1}}[\AA]$ & $\mathbf{2 \Theta}\left[{ }^{\circ}\right]$ \\
\hline PLA/LLDPE/3\% 30B & 34 & 2.6 & $-{ }^{*}$ & $-^{*}$ \\
\hline PLA/LLDPE/4.5\% 30B & 34 & 2.6 & $-{ }^{*}$ & $-{ }^{*}$ \\
\hline PLA/LLDPE/6\% 30B & 34 & 2.6 & $-{ }^{*}$ & $-{ }^{*}$ \\
\hline PLA/LLDPE/3\% 15A & 35.3 & 2.5 & 39.3 & 2.25 \\
\hline PLA/LLDPE/4.5\% 15A & 38.4 & 2.3 & 38.4 & 2.3 \\
\hline PLA/LLDPE/6\% 15A & 39.2 & 2.25 & 38.4 & 2.3 \\
\hline
\end{tabular}

${ }^{*}$ Due to wideness of the peaks, determination of the exact position of the peaks is very difficult.

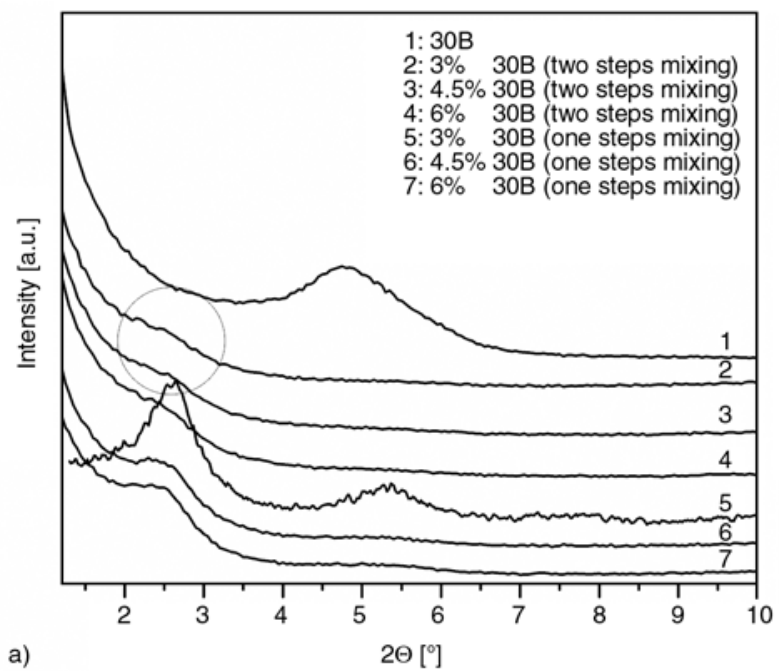

calated structure. All PLA/LLDPE/30B nanocomposites prepared in one step mixing show the same d-spacing.

From Figure 2, the effect of mixing methods on dispersion of nanoclays can be analyzed. To study the dispersibility of clay layers in two phases, the components were mixed in two steps. It can be seen from Figure $2 \mathrm{a}$ that the melt mixing of PLA/30B nanocomposites at different clay contents with pure LLDPE and compatibilizer led to the increase of the gallery spacing which indicates a higher level of silicate layers exfoliation throughout the PLA/LLDPE matrix. It is noticeable that the intensity of diffraction peaks of $30 \mathrm{~B}$ based nanocomposites which were prepared in the two-step mixing procedure is much smaller and wider as compared to other mixing procedure. So practically, it can be concluded that these peaks $\left(2 \Theta=2-2.25^{\circ}\right)$ disappeared in the 30B based nanocomposites prepared by the twostep mixing procedure. It signifies an improved distribution, level of exfoliation and considerable decrease in the ordered clay structure. Although, XRD is very useful tool for the measurement of d-spacing in intercalated systems, combination of XRD and TEM should be utilized for a precise result. In the 15A based blend nanocomposites (PLA/ LLDPE/15A) unlike the 30B based nanocomposites, the d-spacing of silicate layers differs only slightly from that of neat $15 \mathrm{~A}$. It can be due to different cationic modifiers present on the clay surfaces. Comparing to the cationic modifier of the 30B surface, the modifier of Cloisite 15A has less affinity with PLA matrix due to the non-polar nature

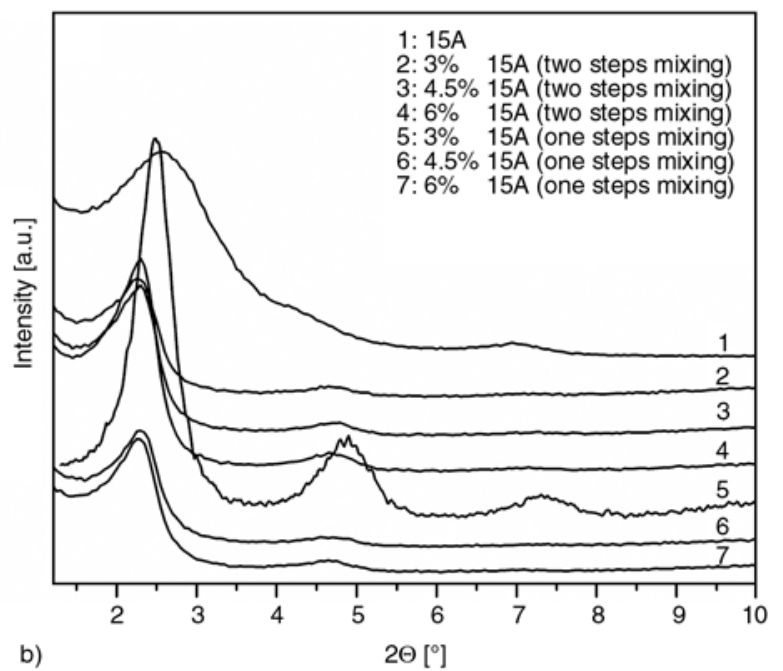

$2 \Theta\left[{ }^{\circ}\right]$

Figure 2. WAXS patterns of pristine organoclays and compatibilized PLA/LLDPE nanocomposites (a) 30B based nanocomposites, (b) 15A based nanocomposites 
of $15 \mathrm{~A}$ and polar nature of PLA. This result confirms that the structure of clay modifier is one of the most important factors that can influence the level of dispersion of nanoclays. The nanocomposites with 3, 4.5 and $6 \mathrm{wt} \% 15 \mathrm{~A}$ content exhibited X-ray peaks similar to the neat Cloisite $15 \mathrm{~A}$ but with different intensities. The extraordinary intensity of the diffraction peak for the nanocomposite with $3 \mathrm{wt} \% 15 \mathrm{~A}$ content may have also been an effect of the sample preparation or local clay order or crystallites.

In PLA/LLDPE/15A based nanocomposites, the characteristic $(001)$ peak of the $15 \mathrm{~A}$ at $2 \Theta=2.55^{\circ}$ appears at $2.5,2.3$ and $2.25^{\circ}$ for hybrids containing $3,4.5$ and $6 \mathrm{wt} \%$, respectively.

In order to study the effect of mixing procedure on selective localization of $15 \mathrm{~A}$, the LLDPE was precompounded with the $15 \mathrm{~A}$ and then the obtained material was added to the PLA and compatibilizer during a second extrusion step. Unlike the 30B based nanocomposites, the effect of mixing procedure on intercalation of silicate layers was not significant. However, slight increase in $\mathrm{d}_{001}$ at lower content of $15 \mathrm{~A}$ ( $3 \mathrm{wt} \%$ ) can be noticed. In other words, the differences between the $\mathrm{d}$-spacing values for all the equivalent loadings of $15 \mathrm{~A}$ at different mixing procedures are relatively small and therefore they all should have similar intercalated structures. It seems that the polar nature of PLA and compatibilizer is responsible for this good level of interaction between 30B and PLA leading to better intercalation/exfoliation of the nanoclay layers. However, it is difficult for XRD to reveal definitive conclusions about the definite structure and particularly localization of the silicate layers in the phases. Thus, TEM technique is necessary to characterize the morphology of the composites.

\subsection{Microscopic analysis}

\subsubsection{TEM analysis}

Combination of XRD and TEM is useful to obtain a precise result. TEM micrographs of PLA/LLDPE nanocomposites with different magnifications are illustrated in Figures 3 and 4. The typical two-phase structure can be seen in these TEM micrographs, in which the dark grey and white parts correspond to LLDPE and PLA phases, respectively. The dark lines are the cross section of the clay layers that have been delaminated and dispersed in the polymer matrix. For the sake of brevity only TEM analy- sis of PLA/LLDPE nanocomposites containing $4.5 \mathrm{wt} \%$ nanoclays are shown here because all the LLDPE/PLA based nanocomposites at different clay contents show almost similar behavior.

The TEM images for PLA/LLDPE/30B based nanocomposites presented in Figure $3 a-3 c$ are indicative of an intercalated/exfoliated structure. Some partly exfoliated clay platelets are located at the interface between PLA and LLDPE. But, besides the exfoliated organoclay layers, some organoclay stacks are also visible, mostly in the PLA phase (Figure 3a and $3 \mathrm{c}$ ). These stacks are responsible for the XRD pattern corresponding to the non-exfoliated organoclay seen from the XRD results of this sample.

The sequence of the addition of components is of importance and can have a strong effect on the localization of nanoclay. In one step mixing method as all the components were added simultaneously to the extruder, the process is complex involving mixtures of solids and viscous fluids and the simultaneous evolution of the morphology of the polymer blend together with the dispersion and migration of the particles inside the molten material [19]. Since the compatibilizer melts at temperature significantly lower (approximately at $75^{\circ} \mathrm{C}$ ) than the other two polymers, it encompasses the 30B nanoparticles preferentially. It can be seen from Figure $3 \mathrm{a}-3 \mathrm{c}$ that the main part of nanoclay is localized at the interface between PLA and LLDPE. However, some of the 30B particles are observed to have crossed the interface and distributed in PLA matrix. This implies that the adsorbed compatibilizer macromolecules on clay surface are desorbed by PLA macromolecules. It seems that due to high barrier energy for desorption and short mixing time, some 30B particles reside at the interface [24].

In the two steps mixing method (Figure $3 \mathrm{~d}-3 \mathrm{f}$ ), first the $30 \mathrm{~B}$ particles were incorporated in to the PLA having higher affinity and then the mixture was compounded with LLDPE and compatibilizer in a separate mixing run. Figure $3 \mathrm{~d}-3 \mathrm{f}$ shows that unlike the one step mixing, $30 \mathrm{~B}$ are distributed mainly within PLA phase in the two steps mixing method. Some partly exfoliated clay platelets within PLA phase are also visible (Figure $3 \mathrm{f}$ ). As it can be seen from Figure 3 the level of exfoliation is better in two step mixing and this is consistent with the wider and lower diffraction peak appearing in the XRD pattern of the equivalent samples which were 

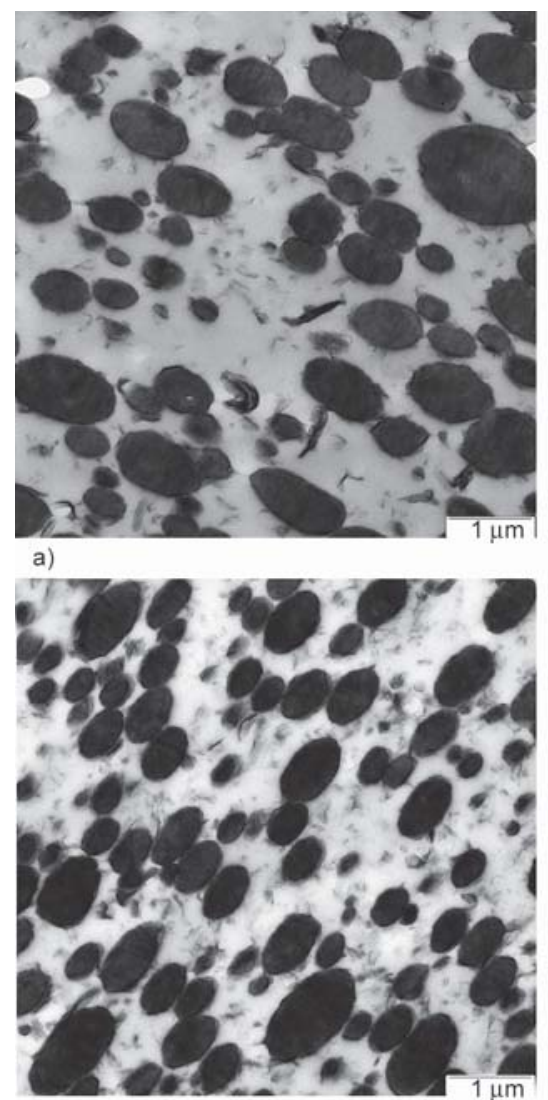

d)

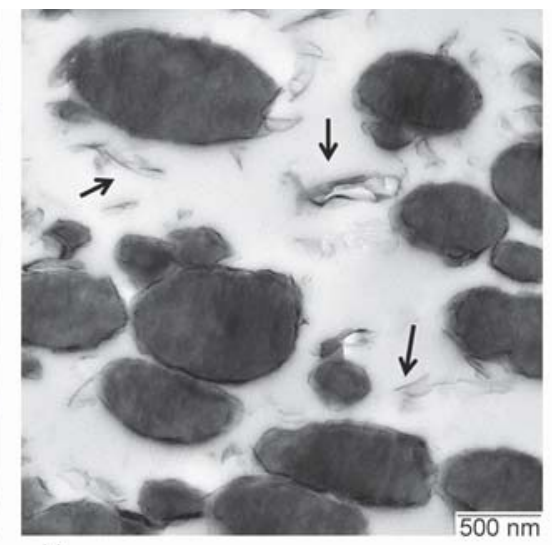

b)

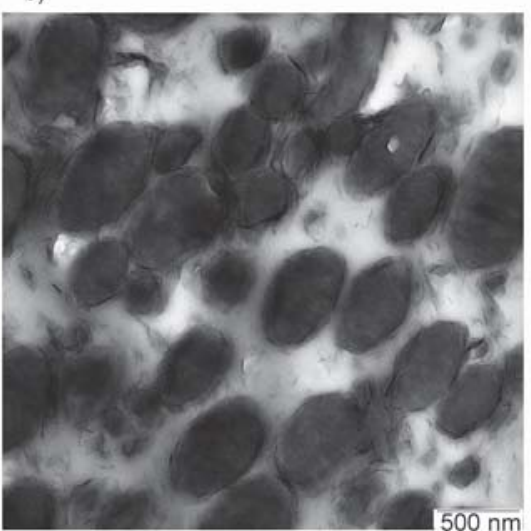

e)

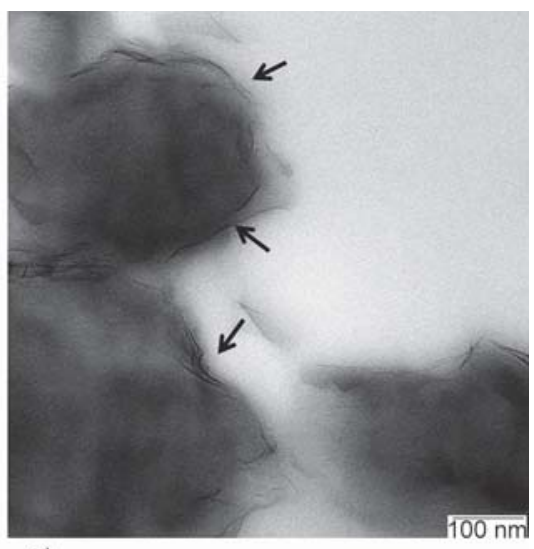

c)

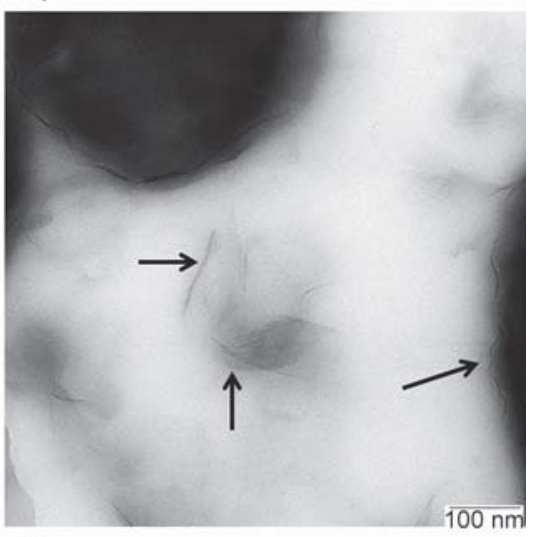

f)

Figure 3. TEM micrographs of compatibilized PLA/LLDPE nanocomposites $(a-c)$ prepared through one step mixing at different magnifications, (d-f) prepared through two steps mixing at different magnifications (all samples contain $4.5 \mathrm{wt} \%$ 30B). (Modified in 15 of April 2020).

prepared through one step mixing, as shown in Figure $2 \mathrm{a}$ curve 3 . It is noticeable that some partly exfoliated clay platelets are also localized at the interface between PLA and LLDPE.

The TEM micrographs of PLA/LLDPE/15A based nanocomposites prepared through different methods are shown in Figure 4a-4f. In 15A based nanocomposites unlike the 30B based nanocomposites, the organoclay is localized mainly at the interface while only small tactoids are observable in the PLA phase. The main reason behind this might be the lesser affinity of $15 \mathrm{~A}$ with PLA phase. Significant difference is not observed between the samples which were prepared through different methods. In both the mixing methods, the nanoclays are localized mainly at the interface. The clay is well distributed at the interface and a few larger tactoids are observable plus some exfoliated single sheets.

Through two steps mixing, one can discern larger amount of tactoids in PLA phase. Since in two step mixing, the $15 \mathrm{~A}$ particles are added first to LLDPE followed by compounding with the PLA and compatibilizer, these particles are embedded in LLDPE phase. The migration of nanoclays from the matrix to the dispersed phase takes place more easily than from dispersed droplet to the matrix. However it is quite evident that migration of nanoclays from the matrix to the dispersed phase is not the only possible migration type [25]. It is interesting to underline that in spite of higher affinity between LLDPE and $15 \mathrm{~A}$, no localization of this organoclay within LLDPE phase is observed in any sample obtained by different mixing methods. One possible reason for this behavior is the higher viscosity of LLDPE than that of the PLA (as it will be seen later), due to which the diffusion of the PLA chain around and into the nanoclay aggregates can be more easily compared with that of the LLDPE at the initial stage of melt mixing.

On the other hand, most of the nanoclays have a tendency to be further dispersed on the phase interface driven by the mixing flow because the carboxylic group of modifier on surface of the nanoclays has good affinity to both the PLA and the compatibilizer phases. As it can be seen from Figure $4 \mathrm{~b}$ the nanoclays are distributed in the phase 


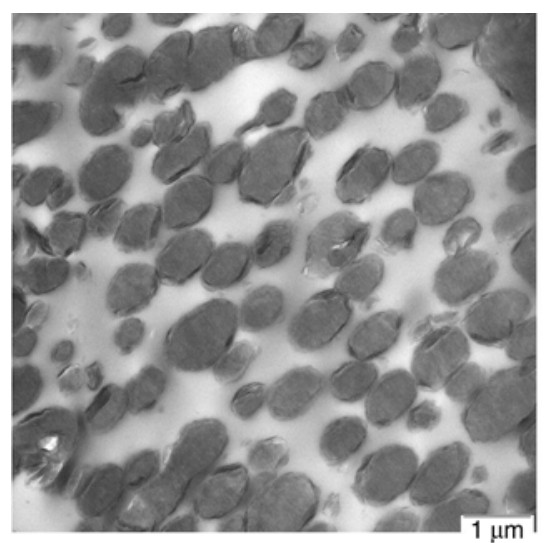

a)

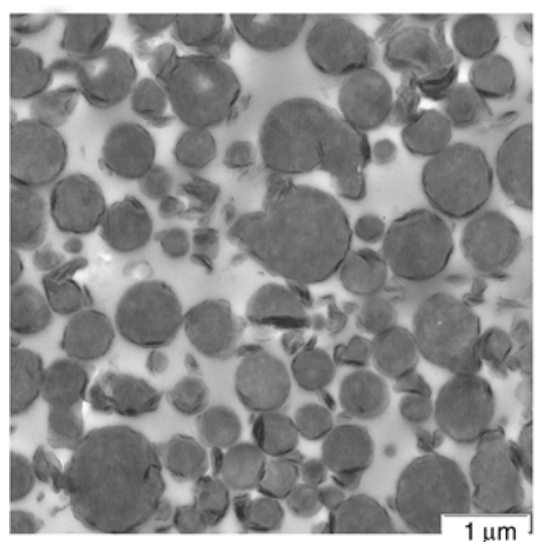

d)

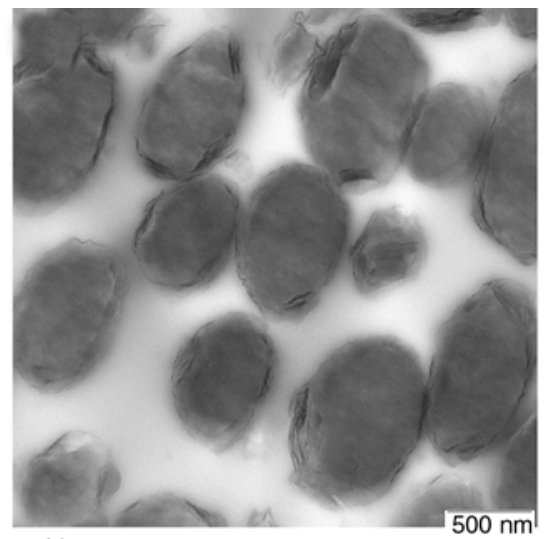

b)

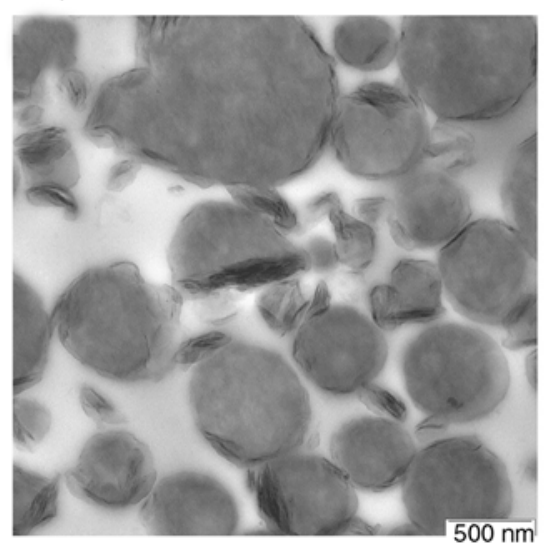

e)

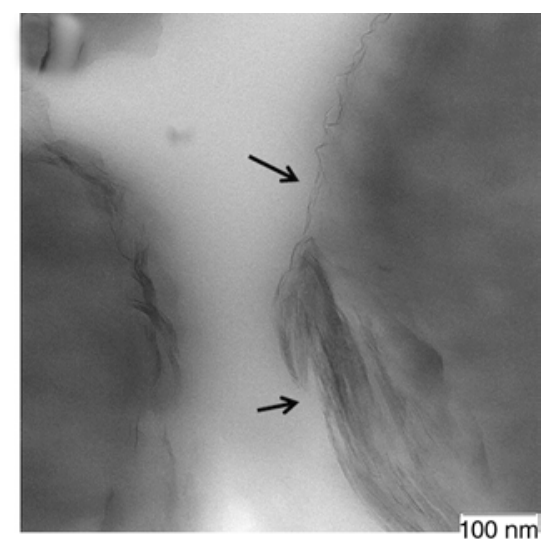

c)

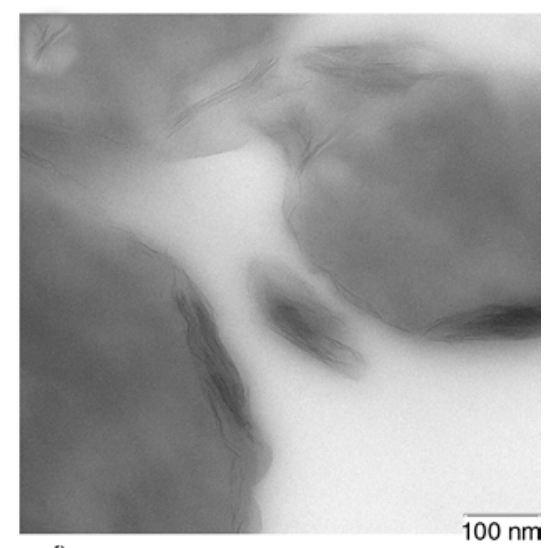

f)

Figure 4. TEM Micrographs of PLA/LLDPE/15A based nanocomposites (a-c) prepared through one step mixing at different magnifications, $(\mathrm{d}-\mathrm{f})$ prepared through two steps mixing at different magnifications (all samples contain $4.5 \mathrm{wt} \% 15 \mathrm{~A})$

interface layer and arranged more or less ordered along the surface of the LLDPE droplets, acting as the emulsifier [26] to enwrap the discrete domains. This interfacial localization of the nanoclays could prevent the coalescence of the LLDPE domains effectively which helps compatibilization during melt mixing. Therefore, both the thermodynamically and kinetically driven compatibility is possible to occur $[27,28]$. Such interface localization of the nanoclays, as a result, improves the interfacial adhesion of the PLA/LLDPE blend matrix evidently as confirmed by the SEM micrographs presented Figures 6 and 7.

Comparing the dispersion of these nanocomposites through different mixing methods one can conclude that mixing of the components in two steps has no influence or literally has only a very marginal effect on the state of dispersion of the nanoclays in all these materials. However the localization of the main part of the nanoclay was different significantly in 30B based nanocomposites prepared through different mixing methods.

\subsubsection{SEM analysis}

SEM micrographs of the cryo-fractured surfaces provide morphological information complementary to the TEM results. The corresponding SEM micrographs of the cryo-fractured surface for the neat PLA/LLDPE, 30B and 15A based nanocomposites through different mixing methods are presented in Figures 5, 6 and 7, respectively. It can be seen from

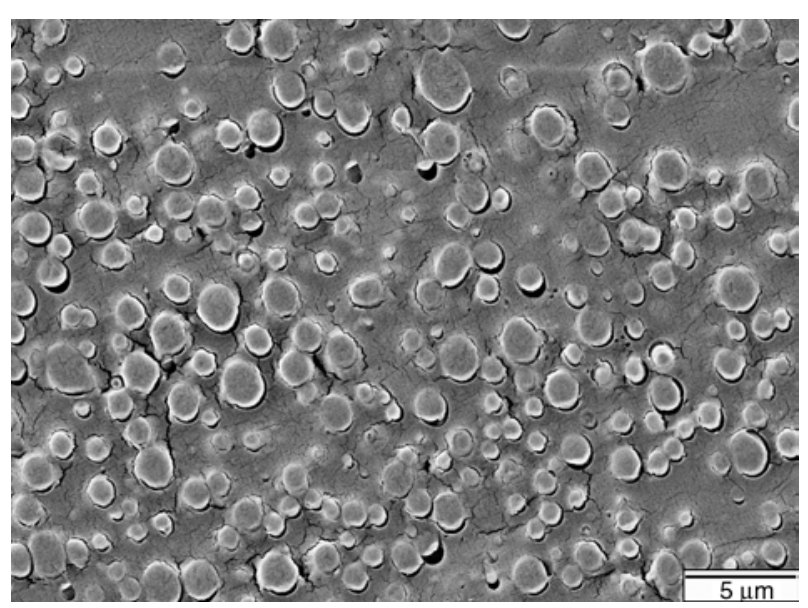

Figure 5. SEM micrographs of compatibilized PLA/LLDPE blend 


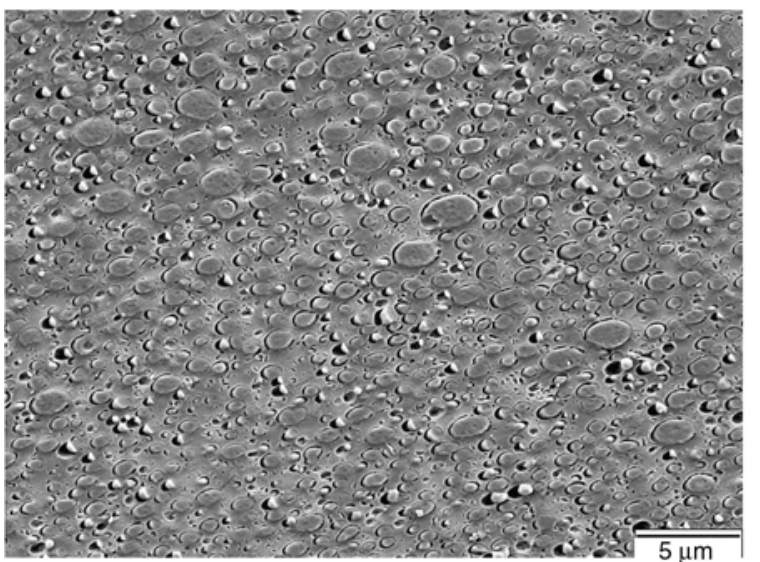

a)

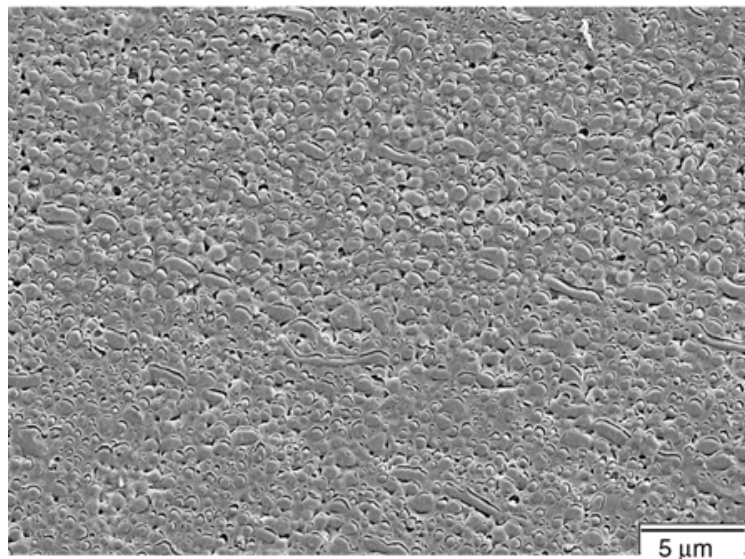

b)

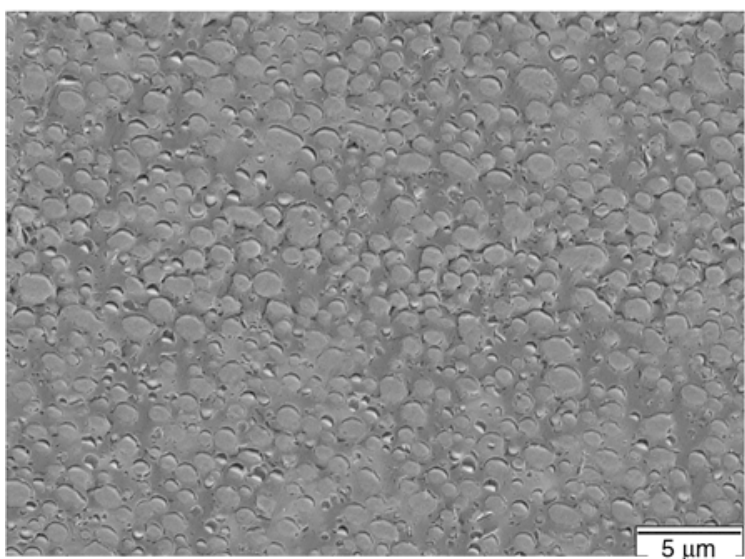

c)

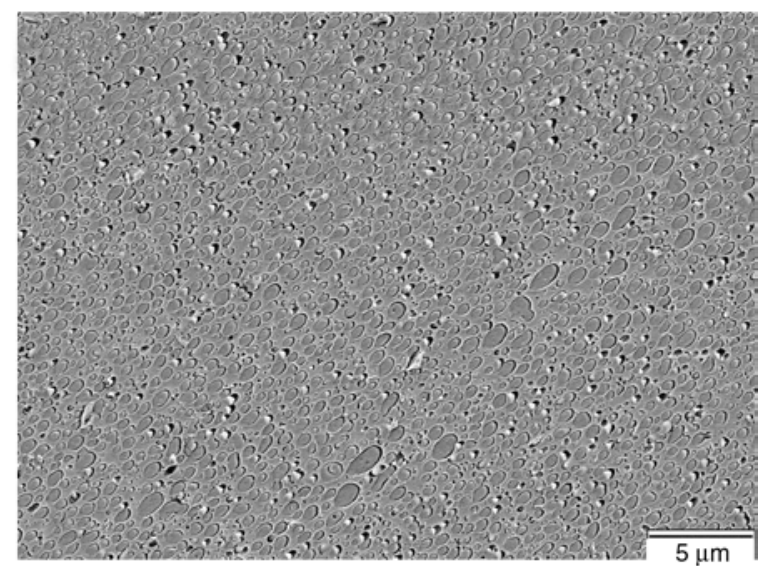

d)

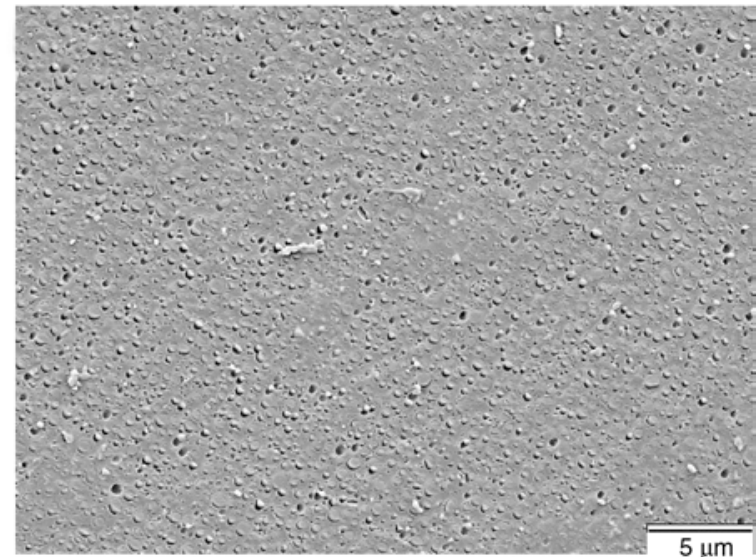

e)

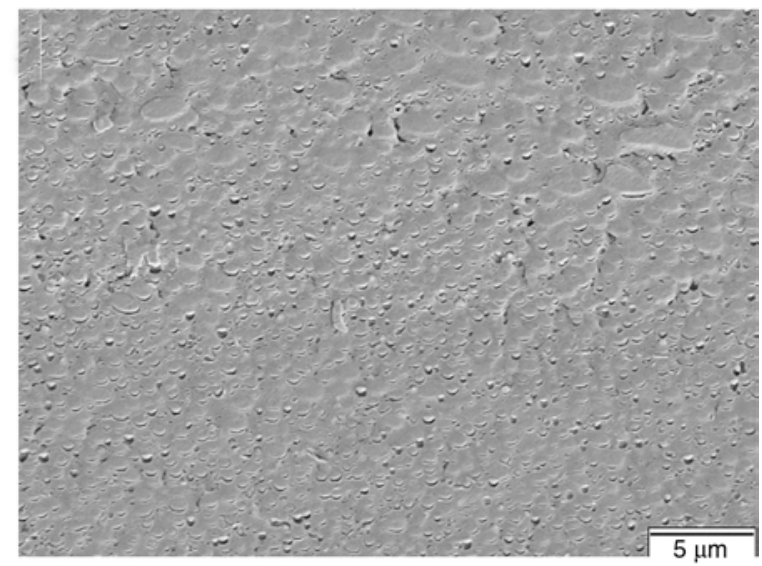

f)

Figure 6. SEM micrographs of compatibilized PLA/LLDPE/30B based nanocomposites, through one step mixing: (a) $3 \mathrm{wt} \% 30 \mathrm{~B}$, (b) $4.5 \mathrm{wt} \%$ 30B, (c) $6 \mathrm{wt} \% 30 \mathrm{~B}$; through two steps mixing: (d) $3 \mathrm{wt} \% 30 \mathrm{~B}$, (e) $4.5 \mathrm{wt} \% 30 \mathrm{~B}$, (f) $6 \mathrm{wt} \% 30 \mathrm{~B}$

the SEM micrographs that all the samples have typical droplet-in matrix morphologies. The size of dispersed particles in all the samples which prepared for SEM was measured by Scandium software (Olympus Soft Imaging Solutions $\mathrm{GmbH}$ ). The number of measurements for each series was 60 particles. The number of the particles per $\mathrm{cm}^{2}$ was approximately 8000000 particles. The data corre- sponding to the average particle size (D) are presented in Table 2.

A size reduction of the dispersed phases can be seen with addition of 30B nanoclays compared with neat PLA/LLDPE. The lower droplet sizes of the dispersed phase for nanocomposites could be due to reduction of the interfacial energy and inhibition of coalescence by the presence of a solid barrier around 


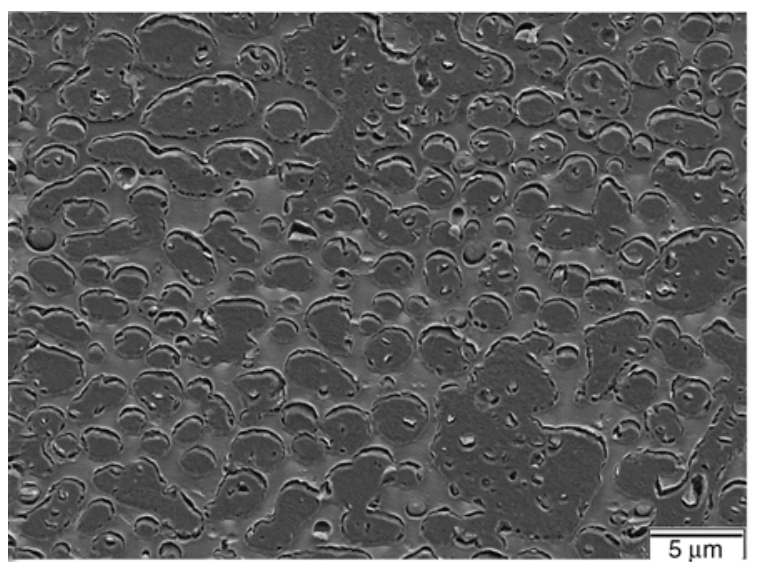

a)

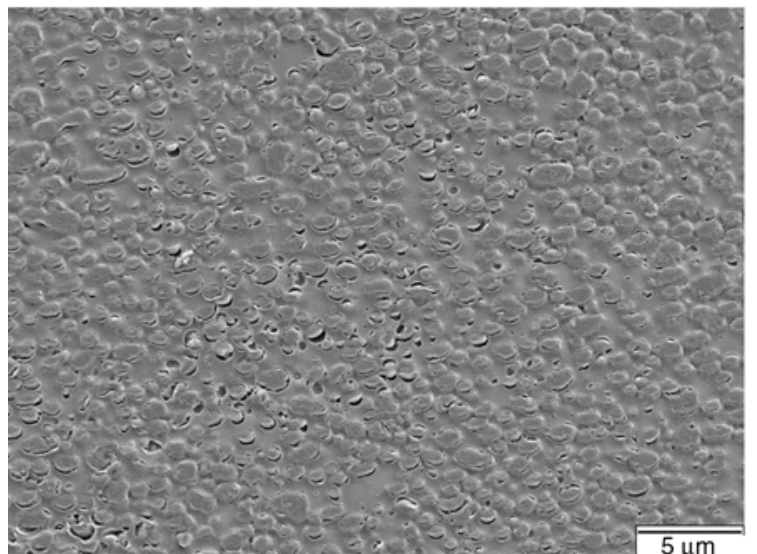

b)

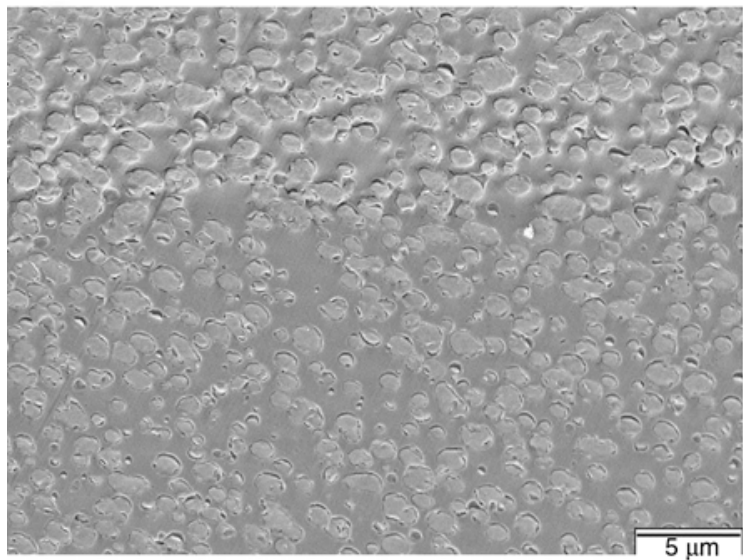

c)

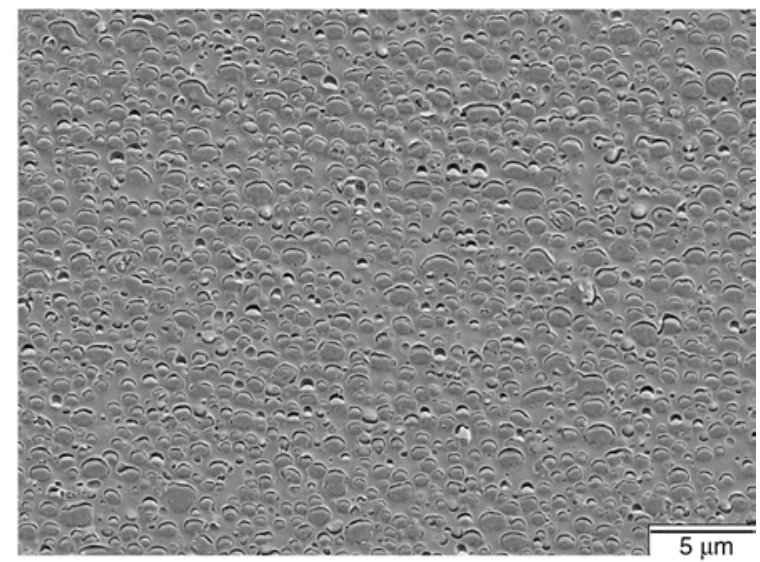

d)

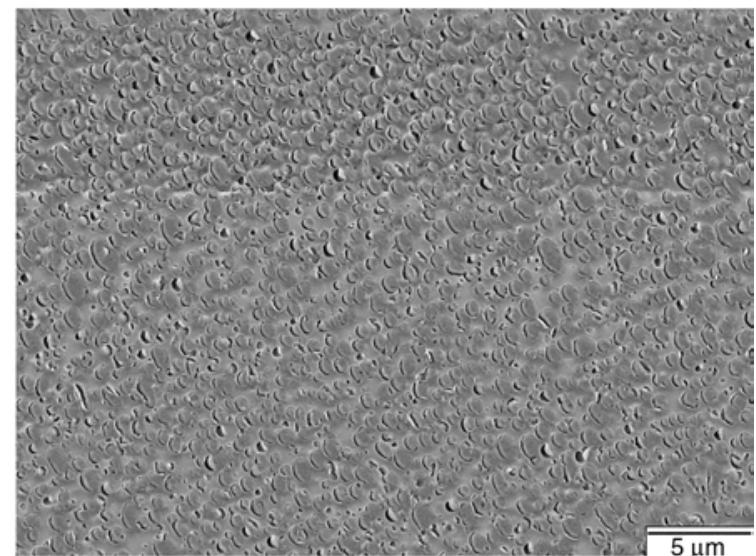

e)

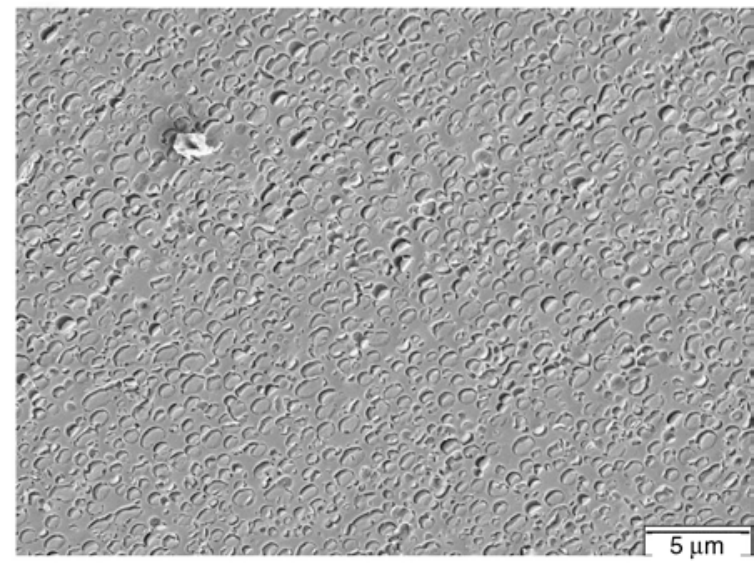

f)

Figure 7. SEM micrographs of compatibilized PLA/LLDPE/15A based nanocomposites, through one step mixing: (a) 3 wt $\% 15 \mathrm{~A}$, (b) $4.5 \mathrm{wt} \% 15 \mathrm{~A}$, (c) $6 \mathrm{wt} \% 15 \mathrm{~A}$; through two steps mixing: (d) $3 \mathrm{wt} \% 15 \mathrm{~A}$, (e) $4.5 \mathrm{wt} \% 15 \mathrm{~A}$, (f) 6 wt $\% 15 \mathrm{~A}$.

the dispersed phase or some partly localization of nanoclays at the interface as evidenced by TEM results (Figure 3). On the other hand, localization of organoclay at the interface of the blend is one of the equisetic mechanisms of size reduction of the dispersed phase. Unlike the 30B, the incorporation of $15 \mathrm{~A}$ to PLA/LLDPE system leads to increase of the dispersed phase from 0.87 to $2.3 \mu \mathrm{m}$. As it can be seen from Table 2 no reduction of dispersed phase are observable in $15 \mathrm{~A}$ based nanocomposites at different mixing methods. This could be explained by the localization of the main part of the $30 \mathrm{~B}$ in the PLA phase which enhance the PLA viscosity (the addition of 30B increases the viscosity of the blend which will be seen later and also better exfoliation of this type of nanoclay in the matrix comparing to the $15 \mathrm{~A}$ as evidenced by the XRD and TEM results. 
Table 2. Average particle size of compatibilized PLA/LLDPE blend and its nanocomposites

\begin{tabular}{|l|c|c|c|c|}
\hline \multirow{2}{*}{ Samples } & \multicolumn{4}{|c|}{ Average particle size $[\mu \mathrm{m}]$} \\
\cline { 2 - 5 } & $\begin{array}{c}\text { One step } \\
\text { mixing }\end{array}$ & $\begin{array}{c}\text { Standard } \\
\text { deviation }\end{array}$ & $\begin{array}{c}\text { Two steps } \\
\text { mixing }\end{array}$ & $\begin{array}{c}\text { Standard } \\
\text { deviation }\end{array}$ \\
\hline PLA/LLDPE & 0.87 & 0.13 & - & - \\
\hline $3 \% 30 \mathrm{~B}$ & 0.73 & 0.32 & 0.59 & 0.18 \\
\hline $4.5 \% 30 \mathrm{~B}$ & 0.65 & 0.28 & 0.56 & 0.13 \\
\hline $6 \% 30 \mathrm{~B}$ & 0.95 & 0.26 & 0.67 & 0.26 \\
\hline 3\% 15A & 2.30 & 0.74 & 0.94 & 0.33 \\
\hline $4.5 \% 15 \mathrm{~A}$ & 1.15 & 0.37 & 0.92 & 0.30 \\
\hline $6 \% 15 \mathrm{~A}$ & 1.06 & 0.35 & 0.76 & 0.26 \\
\hline
\end{tabular}

Furthermore the difference in the dispersed phase particle size for the $30 \mathrm{~B}$ and $15 \mathrm{~A}$ based nanocomposites is presumably due to the superior ability of the nanoclay modifiers with the PLA to suppress the coalescence. Due to the better affinity of 30B modifier with PLA, one should note that at higher content of nanoclays $(6 \mathrm{wt} \%)$, the reduction of dispersed particle size is not significant (Figures $6 \mathrm{c}, 6 \mathrm{~d}$ and $7 \mathrm{c}, 7 \mathrm{f})$. It can be attributed to the agglomeration of nanoclays at higher loading of nanoclays. In the case of the samples prepared through two steps mixing, a uniform dispersion of the LLDPE droplets with finer sizes can be observed. This could be the result of the longer mixing time during two steps extrusion or localization of the main part of the nanoclays in the PLA phase which can affect the viscosity of the matrix.

\subsection{Rheological behavior}

For optimization of the polymer processing conditions the knowledge of melt rheological behavior is necessary. As the rheological behavior of multi phase system is intimately related to its morphology, in this section we investigate how these morphological differences influence the rheological behavior of this multiphase system. The complex viscosity $\left(\eta^{*}\right)$, storage modulus $\left(G^{\prime}\right)$ and loss modulus $\left(G^{\prime \prime}\right)$ as a function of frequency of blend components and compatibilized PLA/LLDPE nanocomposites at $180^{\circ} \mathrm{C}$ are presented in Figures 8,9 and 10 . Regarding the rheological behavior, the complex viscosity of the neat blend without clay is higher than those of the individual components. Considering the viscosities of blend components it is seen that the reactive PLA/LLDPE/Elvaloy PTW blend has higher viscosity than the values predicted by a linear mixing rule. This can be due to the effect of reactive compatibilization.
As it can be seen from Figure 8 the neat blend as well as the blend components shows shears thinning behavior at higher frequency. However, a short Newtonian plateau can be identified in viscosity curves of PLA/LLDPE and blend components at low frequency. The rheological behavior of the blends with nanoclay is quite different. On comparing the melt viscosity of compatibilized PLA/LLDPE blend and its nanocomposites it is found that the span of the Newtonian plateau region shrinks (especially at low frequencies) with the addition of nanoclays. The melt behaviors of the PLA/LLDPE nanocomposite indicate their typical non-Newtonian viscosity behavior. The PLA/LLDPE nanocomposites exhibits shear thinning behavior in the complex viscosity curve.

It is well known that the presence of fillers in polymer melts not only increases their shear viscosity but also affects their shear rate dependency [30]. By fitting power law model (which is mostly used for many kinds of nanocomposites) to the viscosity curve of PLA/LLDPE nanocomposites, the values of $n$ for PLA/LLDPE nanocomposites were calculated and listed in Table 3.

Figures $8 \mathrm{a}$ and $8 \mathrm{~b}$ show that by increasing the nanoclay contents the complex viscosity of PLA/LLDPE blend increases monotonically. However, this increase at higher content of nanoclays (at least $4.5 \mathrm{wt} \%$ ) is less pronounced. This change in behavior towards a solid like behavior can be attributed to the morphological changes i.e. refinement of the dispersed phase by addition of nanoclays to this system [29]. Referring to the SEM micrographs due to agglomeration of nanoclay particles at higher loading, the significant refinement of the dispersed phase is not observable (Figures 6c and 7c).

Contrary to $30 \mathrm{~B}$, different loadings of $15 \mathrm{~A}$ do not show significant effect on viscosity behavior. In other words the viscosity behavior of PLA/LLDPE/ $15 \mathrm{~A}$ based nanocomposite is almost the same especially at higher frequency. It seems that for this system at least $3 \mathrm{wt} \% 15 \mathrm{~A}$ is the optimum clay loading for solid like behavior. However, from Figures 8 and Table 3 one can notice that the extent of shear thinning behavior of PLA/LLDPE/15A based nanocomposites appears to be slightly higher than that for 30B based nanocomposites. Moreover, the complex viscosity of the PLA/LLDPE/15A based nanocomposites is lower than 30B based nanocom- 

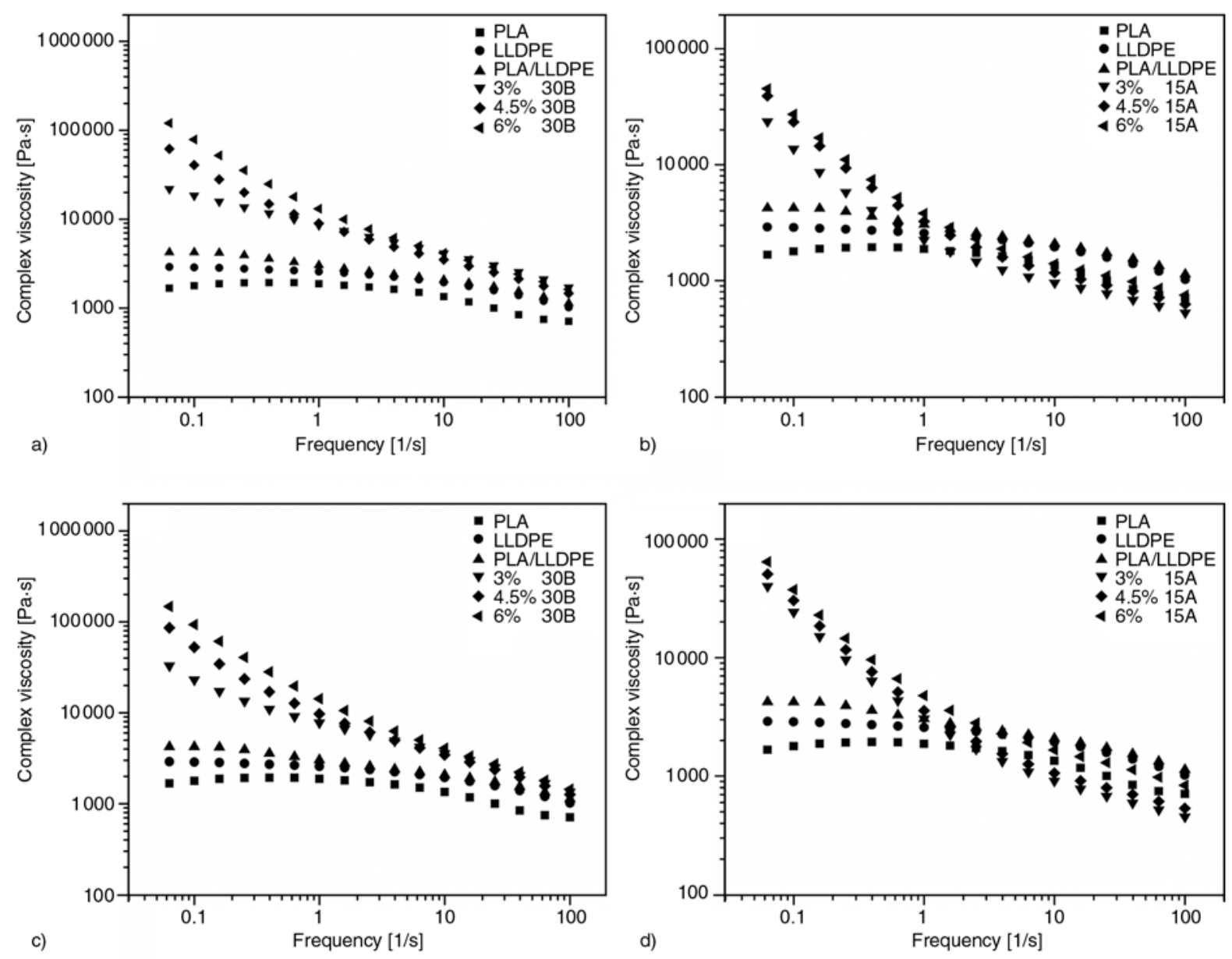

Figure 8. Complex viscosity as a function of frequency for PLA/LLDPE blend nanocomposites prepared via: (a) and (b) one step mixing, (c) and (d) two steps mixing

posites and also less than that of neat PLA/LLDPE blend when a shear rate of $1[1 / \mathrm{s}]$ was reached.

The observed lower viscosity of $15 \mathrm{~A}$ nanocomposites as compared to $15 \mathrm{~B}$ based samples in the first look might seems to be related to the matrix degradation, however it has been reported that both $15 \mathrm{~A}$ and $30 \mathrm{~B}$ have limited neutralizing capacity of the acids produced during hydrolytic degradation and hence, no huge differences were observed between the two fillers on matrix hydrolytic degradation [38]. Therefore the observed lower viscosity of $15 \mathrm{~A}$ based nanocomposites as compared to $30 \mathrm{~B}$ based

Table 3. Power law exponent of PLA/LLDPE nanocomposites

\begin{tabular}{|l|c|c|}
\hline \multirow{2}{*}{ Samples } & \multicolumn{2}{c|}{ Power low exponent (n) } \\
\cline { 2 - 3 } & One step mixing & Two steps mixing \\
\hline PLA/LLDPE/3\% 30B & 0.67 & 0.61 \\
\hline PLA/LLDPE/ 4.5\% 30B & 0.53 & 0.47 \\
\hline PLA/LLDPE/ 6\% 30B & 0.44 & 0.40 \\
\hline PLA/LLDPE/ 3\% 15A & 0.53 & 0.41 \\
\hline PLA/LLDPE/ 4.5\% 15A & 0.47 & 0.40 \\
\hline PLA/LLDPE/ 6\% 15A & 0.48 & 0.45 \\
\hline
\end{tabular}

samples may be due to the higher level of fillerpolymer interaction in the $30 \mathrm{~B}$ based system.

Figures $8 \mathrm{c}$ and $8 \mathrm{~d}$ show the viscosity behavior of nanocomposites which were prepared through two steps mixing. As it is seen nanocomposites prepared through two steps mixing show similar trend in viscosity behavior comparing to the nanocomposites with the equivalent loadings of nanoclays prepared via one step mixing method. However, the nanocomposites prepared via two steps mixing show higher viscosity. This can be due to the main localization of $30 \mathrm{~B}$ and some partly localization of $15 \mathrm{~A}$ in the PLA matrix depicted in TEM images (Figures 3 and 4). Figure $9 \mathrm{a}$ depicts an increase of storage modulus with increase in frequency for neat PLA/ LLDPE blend comparing with blend components. Furthermore the storage modulus of nanocomposites is even much higher than the neat blend and the development of a plateau in storage modulus is observable in case of nanocomposites. As it can be seen from Figure 9a, with increasing the 30B content, the storage modulus of nanocomposites enhances. 

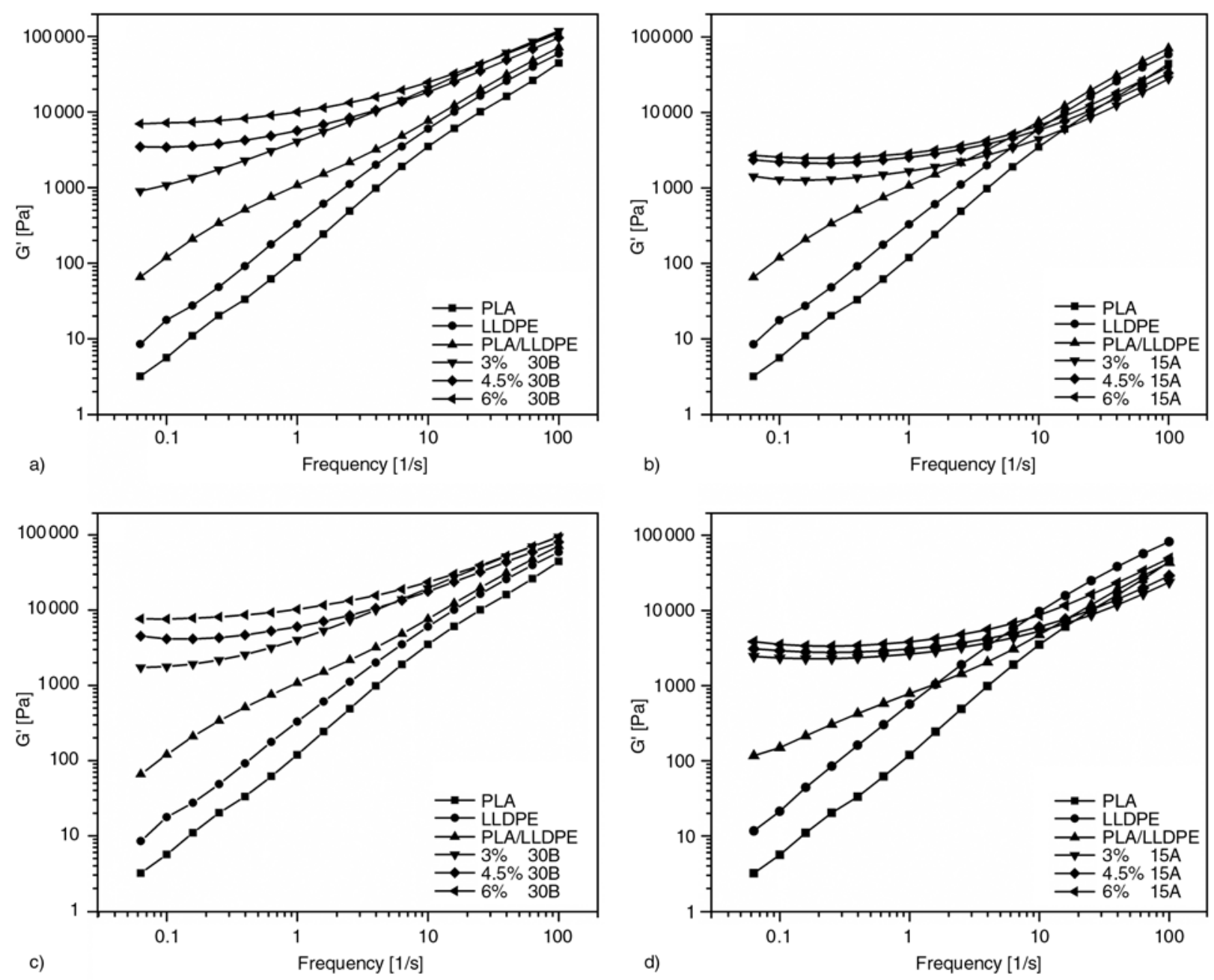

Figure 9. Storage modulus $\left(G^{\prime}\right)$ as a function of frequency for PLA/LLDPE blend nanocomposites prepared via: (a) and (b) one step mixing, (c) and (d) two steps mixing

At $4.5 \mathrm{wt} \%$ 30B loadings the frequency dependence nearly disappears at lower frequency. This non-terminal behavior is due to formation of gel structure which highly restrains the long-range relaxation of the matrix PLA chains. However, the enhancement of elasticity of $6 \mathrm{wt} \% 30 \mathrm{~B}$ comparing to $4.5 \mathrm{wt} \%$ $30 \mathrm{~B}$ is not remarkable. This can be attributed to agglomeration of 30B nanoclays at higher loadings of nanoclay. At higher content of 30B, although the clay is aggregated, the elastic properties enhance slightly.

Unlike the 30B based nanocomposites, in $15 \mathrm{~A}$ based nanocomposites the remarkably enhanced elasticity is not found by increasing the clay content. This may be due to the less interaction of the PLA/15A and internal structure of the PLA/LLDPE/ 15A based nanocomposites. As evidenced by the SEM results the particle size of dispersed phase in $15 \mathrm{~A}$ based nanocomposites is higher than that of $30 \mathrm{~B}$ based nanocomposites. Additionally, the smaller the

size of particles (thus the larger surface area of particles) in a nanocomposite, the lower the concentration of the filler will be that may give rise to elasticity and shear thinning behavior [31].

The loss modulus of blend nanocomposites show similar trend at different nanoclays content (Figure 10). However, due to elasticity the differences in storage modulus are more remarkable. From Figure 9 and 10, one can notice that the storage modulus $\left(G^{\prime}\right)$ is higher than loss modulus $\left(G^{\prime \prime}\right)$ at high frequency region for both the blend and nanocomposites. In the case of samples prepared via the two steps mixing (Figures 9c and 9d and 10c and 10d), all the nanocomposites (30B and 15A based nanocomposites) show higher storage and loss modulus compared to the samples prepared via the one step process.

Furthermore the Cole-Cole plots were used in order to examine the structural changes in the nanocomposites at constant temperature. Figure 11 shows 

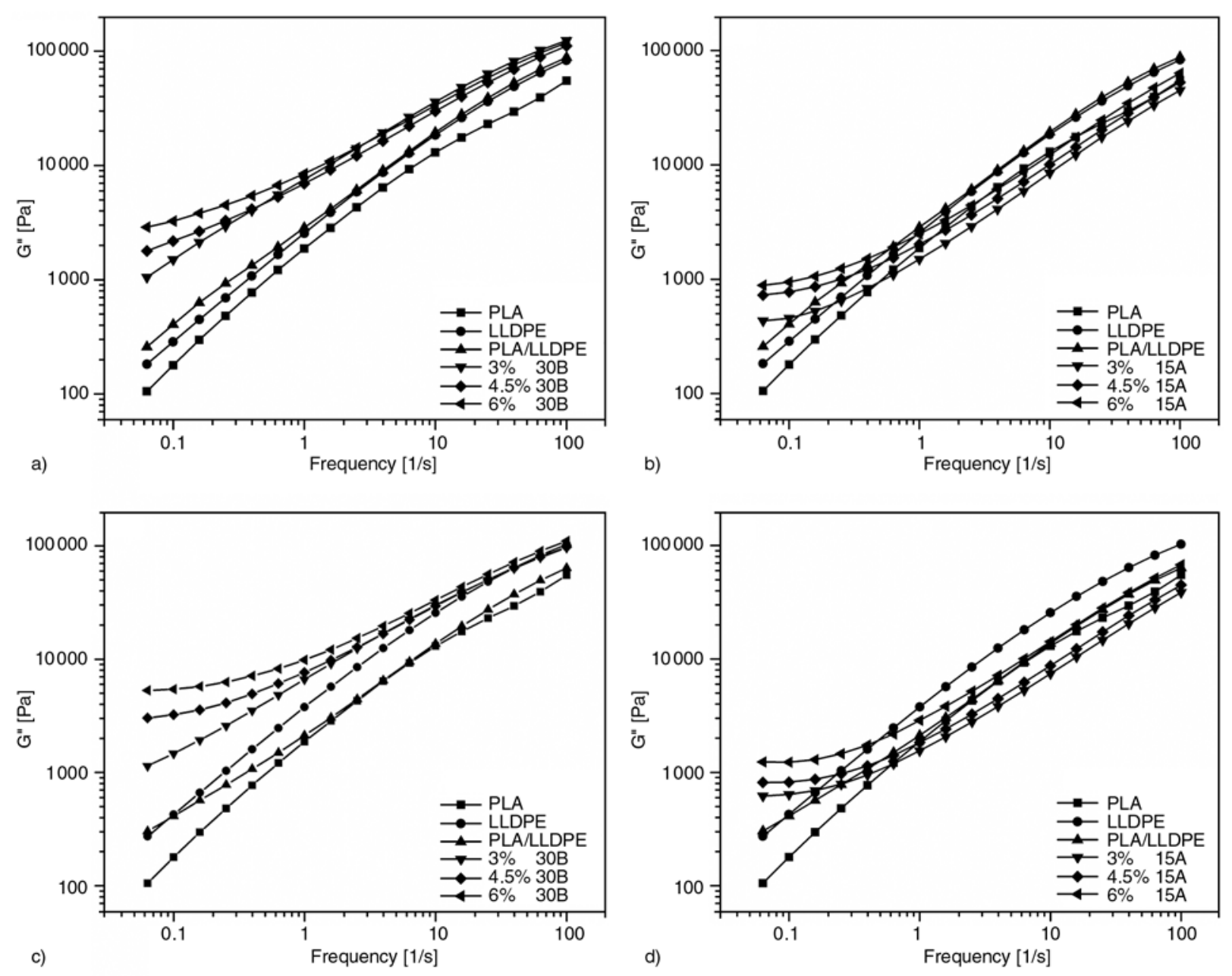

Figure 10.Loss modulus $\left(G^{\prime \prime}\right)$ as a function of frequency for PLA/LLDPE blend nanocomposites prepared via: (a) and (b) one step mixing, (c) and (d) two steps mixing
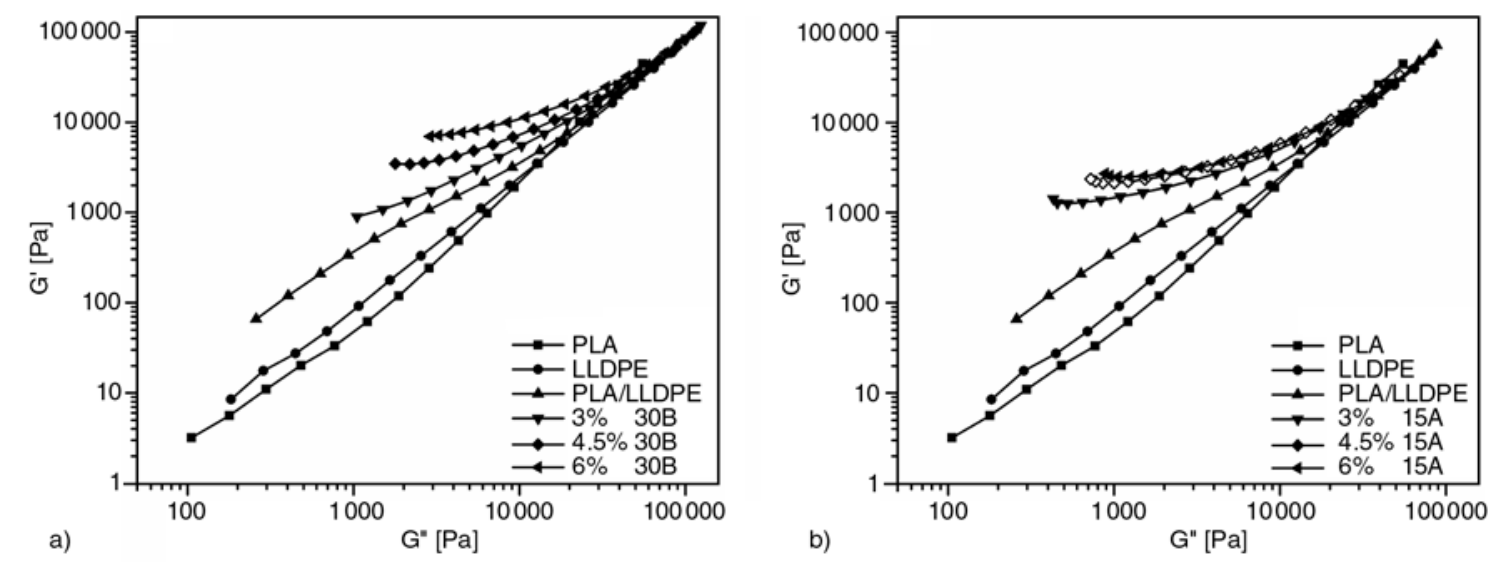

Figure 11. Cole-Cole plots for PLA/LLDPE nanocomposites: (a) 30B based nanocomposites, (b) 15A based nanocomposites prepared via one step mixing

the Cole-Cole plots of PLA/LLDPE blend and nanocomposites prepared by one step mixing process. Neat PLA and LLDPE show characteristic homopolymer-like terminal flow behavior, (terminal zone slope is about 2). The deviation between PLA/LLDPE blend and its nanocomposites shows structural changes from liquid-like to solid-like with increasing the clay content. This can be attributed to the formation of network structures.

The 30B based nanocomposites show such structure at $4.5 \mathrm{wt} \%$ of nanoclay. Additionally, as the clay content is increased, a distinctively larger devi- 
ation is observed as compared to the PLA/LLDPE blend.

Unlike the 15A based nanocomposites, this deviation is much more pronounced at higher content of 30B and also at different contents of 30B. In other words, the $15 \mathrm{~A}$ based nanocomposites show similar structures at different contents of clay. Furthermore in $15 \mathrm{~A}$ based nanocomposites the solid like behavior (i.e. the plateau region at low frequency) takes place at $3 \mathrm{wt} \%$ 15A loading. Figure 12 shows the Cole-Cole plots for all PLA/LLDPE nanocomposites prepared by different mixing methods. As it can be seen from Figure 12a in 30B based nanocomposites (especially at higher content of $30 \mathrm{~B}$ ) at the equivalent clay content both samples which were prepared via different mixing methods show similar structure. However, through two steps mixing, the development of a plateau in storage modulus at lower loss modulus is observable at lower clay content ( $3 \mathrm{wt} \% 30 \mathrm{~B})$ as compared to the one step mixing. This indicates the significant effect of two steps mixing on formation of a network structure and solid like behavior at lower nanoclay loading. Unlike the 30B based nanocomposites, the effect of mixing methods on the structure is not significant for $15 \mathrm{~A}$ based nanocomposites. As it can be seen the deviation between the structures is not remarkable. All the 15A based nanocomposites prepared via different mixing methods with equal clay content show similar structures. These findings further confirm the morphological finding concerning the stronger effect of mixing procedure on properties in the 30B based nanocomposites than in 15A.

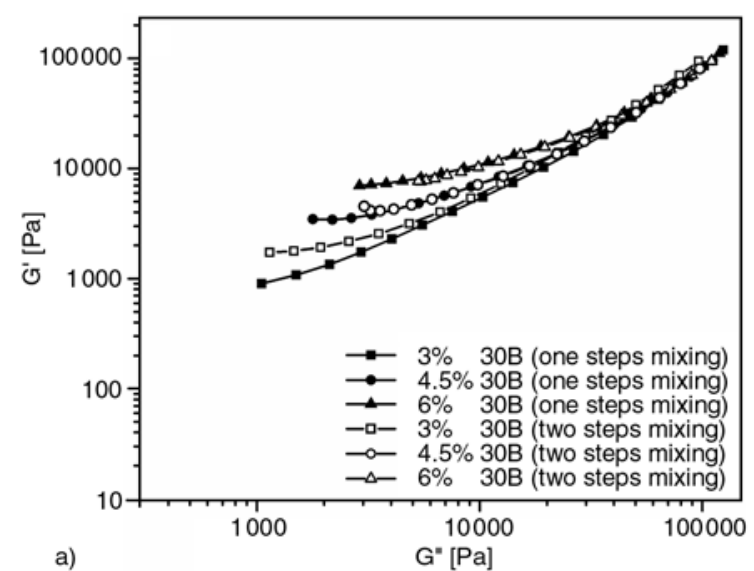

Figure 12. Cole-Cole plots for PLA/LLDPE nanocomposites: ites prepared via different mixing methods

\subsection{Biodegradability}

The degradation of polymeric blends especially under environmental conditions is a very important issue from commercialization point of view. More exciting aspect of this research is the biodegradability of PLA in presence of LLDPE and also enhancement of biodegradability of PLA/LLDPE after nanoclay incorporation. In this work, the biodegradation process of all the samples was studied in a compost environment at temperature well above ambient i.e. $58+2^{\circ} \mathrm{C}$. This is because the rate of degradation of pure PLA is very slow at the ambient temperature $[32,33]$. To study the degradation of the PLA/LLDPE blend and its nanocomposites in compost, a respirometric test was done [34, 35].

The residual weight percentages of the initial test samples with time (weight loss), which reflect the structural changes in the test samples, and the rate of biodegradation with time are presented in Figure 13a and 13b, respectively. As it can be seen from Figure 13a within two weeks, the extent of weight loss is almost the same for both pure PLA and PLA/LLDPE blend. However, after two weeks, a change occurs in the weight loss of PLA. The rate of the weight loss increase after one month, and within two months, it is completely degraded in the compost. This confirms the two steps degradation process of PLA. During the initial phases of degradation, the high molecular PLA chains hydrolyze to lower molecular weight oligomers. In the second step, the microorganisms in the environment continue the degradation process by converting these lower molecular weight components to carbon diox-

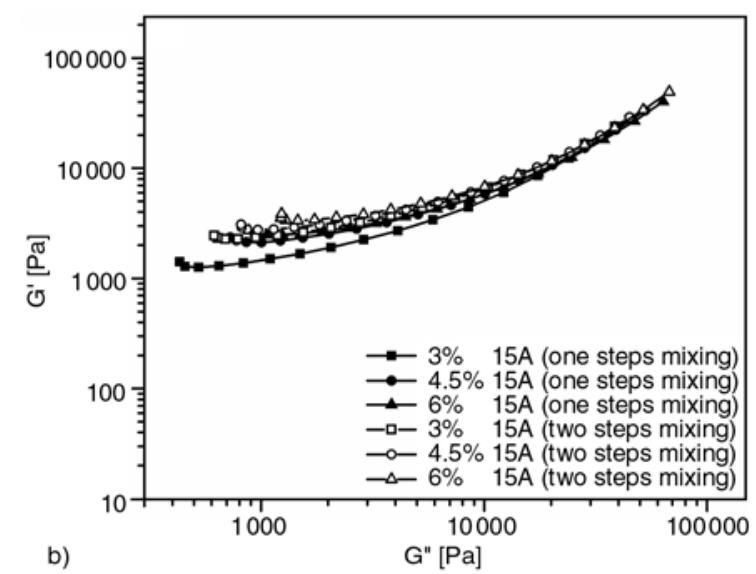
: (a) 30B based nanocomposites, (b) 15A based nanocompos- 

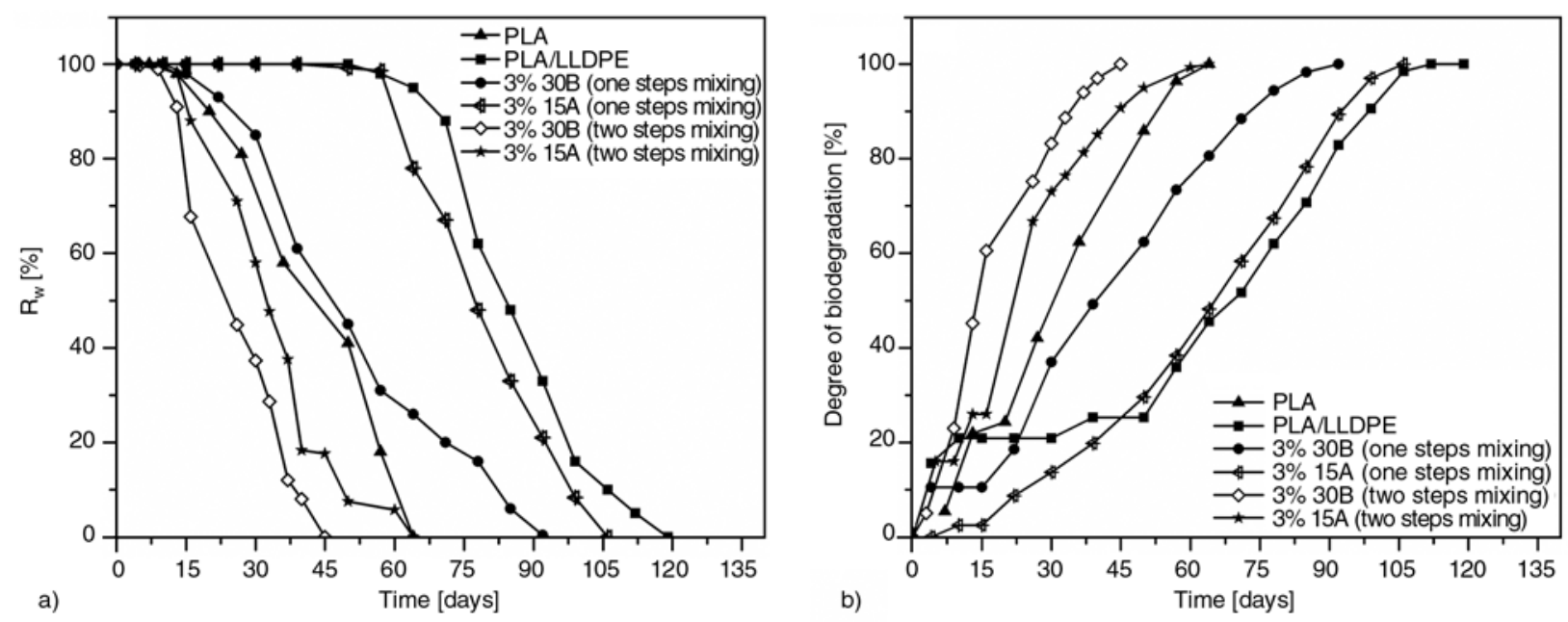

Figure 13. Time-dependence of: (a) weight residual percentage $\left(R_{\mathrm{w}}\right)$; (b) degree of biodegradation $\left(\mathrm{CO}_{2}\right.$ evolution) of pure PLA, PLA/LLDPE and its nanocomposites

ide, water, and humus. Unlike weight loss or fragmentation which reflects the structural changes in the test sample, $\mathrm{CO}_{2}$ evolution provides an indicator of the ultimate biodegradability (Figure 13b). Figure $13 \mathrm{~b}$ shows the rate of carbon dioxide releasing which is the result of the degradation of lower molecular weight components to carbon dioxide and water. As it can be seen from Figure 13b, after two weeks the rate of biodegradability (as a released $\mathrm{CO}_{2}$ ) of PLA has increased. A compost pile is a great source of microbial activity, because it has a high moisture content and temperature. This in turn provides a tremendous amount and variety of organisms able to attack and digest compostable materials. The compost microorganisms continue the degradation process by converting these lower molecular weight components to carbon dioxide and water. The amount of released $\mathrm{CO}_{2}$ and the rate of $\mathrm{CO}_{2}$ evolution are in agreement with the weight loss results. The difference between the starting point of the weight loss and the beginning point of the $\mathrm{CO}_{2}$ evolution can be due to experimental error. Similar result has been reported by other researchers [36]. Furthermore, the PLA/LLDPE blend shows a longer induction time and a lower rate of degradation in comparison with the neat PLA. This can be attributed to the too slow rate of degradation and nondegradability of LLDPE phase dispersed throughout the PLA matrix under compost condition. The results showed that in spite of addition of $25 \mathrm{wt} \%$ LLDPE to the PLA, this blend system can degrade completely under compost condition after 4 months. Interestingly, the biodegradability of the neat PLA/LLDPE blend is significantly enhanced after nanoclay incorporation. This indicates the catalytic role of the clay interfaces in the hydrolytic degradation of PLA chains.

In other words, the presence of terminal hydroxylated edge groups of the silicate layers may be one of the factors responsible for this behavior. In PLA/ LLDPE nanocomposites, the hydroxyl groups of stacked and intercalated silicate layers which are dispersed in the PLA matrix can initiate heterogeneous hydrolysis of the PLA matrix after absorbing water from the compost. This process takes some time to start. For this reason, according to Figure 13a, the weight loss and degree of hydrolysis of PLA/ LLDPE and its nanocomposites is almost similar up to 15 days. However, after 15 days there is a sharp weight loss in the case of PLA/LLDPE/30B nanocomposites prepared through the one step mixing process. This means that those 15 days are critical time to start heterogeneous hydrolysis, and due to this type of hydrolysis the matrix degrades into very small fragments and is eliminated with the compost. Several authors [37-39] supported this conclusion of the catalytic effect of nanoclays on the biodegradation or hydrolytic degradation of PLA. As it is seen from Figure 13, this critical time increases to 60 days in the case of $15 \mathrm{~A}$ based nanocomposites which were prepared through the one step mixing. Comparison of the effects of $30 \mathrm{~B}$ and $15 \mathrm{~A}$ on the rate of biodegradation having somewhat different hydrophilicity, different kinds of modifier and slight filler dispersion differences based on WAXS data (Figure 2) and TEM micrographs (Figures 3a-3c and $4 a-4 c)$, can explain the slightly lower rate constants observed for the 15A based nanocomposites. 
One can notice that at the same time the degree of biodegradation of $30 \mathrm{~B}$ based nanocomposites is nearly two times higher than that of $15 \mathrm{~A}$ based nanocomposites.

Another possible factor that controls the biodegradability of PLA/LLDPE blend is the degree of crystallinity. The degradation of amorphous phase is easier than the crystalline phase. The effect of nanoclays on crystallization behavior of PLA/LLDPE blend has been studied systematically in our previous work and the results showed that 15 A nanoclay is more effective than $30 \mathrm{~B}$ nanoclay in improving the crystallinity of PLA/LLDPE blend. For this reason the effect of 30B nanoclay in enhancement of biodegradability of PLA/LLDPE blend is much more remarkable than $15 \mathrm{~A}$ nanoclay.

In the case of nanocomposites prepared through two steps mixing, due to localization of the main part of the nanoclays in PLA matrix, the enhancement of biodegradability is significant. As it can be seen from Figure 13 the 30B based PLA/LLDPE nanocomposites degrade completely after 45 days. Interestingly the rate of biodegradability of PLA/ LLDPE nanocomposites prepared through two steps mixing is higher than pure PLA. It is to be noted that the higher rate of biodegradability through the two-step mixing process may also be due to reduction of PLA molecular weight as a result of the twostep extrusion process in which PLA is subjected to more intensive shearing at longer times. However, since the main mechanism of PLA degradation is hydrolysis, which is highly under influence of clay presence, the enhanced rate of biodegradation can be mainly attributed to the clay positioning influenced by the two-step mixing process. Unlike the one step mixing, the difference between degradability rate of $15 \mathrm{~A}$ and $30 \mathrm{~B}$ is not too significant. This can be attributed to the different localization of nanoclays induced by the different mixing methods. These data clearly indicate that mixing methods and localization of nanoclays have a significant effect on the rate of biodegradation.

\section{Conclusions}

Two different PLA/LLDPE nanocomposite systems based on two different kinds of nanoclays were prepared through different mixing methods. Comparison of the effects of $30 \mathrm{~B}$ and $15 \mathrm{~A}$ on the morphology of PLA/LLDPE, based on different kinds of modifier and affinity, can explain the lower level of exfoliation and dispersion observed for the 15A based nanocomposites as compared to 30B based nanocomposites. In all the nanocomposites some partly exfoliated clay plates are located at the interface between PLA and LLDPE. Such interfacial localization of the nanoclays, as a result, improves the interfacial adhesion of the PLA/LLDPE blend matrix distinctly and refines the dispersed phase. Unlike $30 \mathrm{~B}$, the influence of $15 \mathrm{~A}$ on the reduction of the dispersed phase is not remarkable. This could be explained by the mainly localization of $30 \mathrm{~B}$ in the PLA phase which enhances the viscosity of PLA and also better exfoliation of this nanoclay in the matrix as compared to the 15A. Through two steps mixing in 30B based nanocomposites, nanoclays localized mainly in PLA phase. In spite of having higher affinity between LLDPE and 15A, no localization of this organoclay within LLDPE phase is observable in 15A based nanocomposites prepared via different mixing methods. Only some portions of 15A migrate to the PLA phase. From the rheological measurement, it is found that the complex viscosity and storage and loss modulus were related to the dispersion state and localization of nanoclays at the nanocomposites. Our results suggest that for 30B based nanocomposites $4.5 \mathrm{wt} \% 30 \mathrm{~B}$ is the optimum loading of nanoclay. However, this amount shifts to lower content (3 wt\%) nanoclay in 15A based nanocomposites. Furthermore the improvement of the rheological properties with increasing the clay contents in 30B based nanocomposites was remarkable compared to the $15 \mathrm{~A}$ based nanocomposites. In the case of samples which were prepared via two steps mixing, all nanocomposites (30B and $15 \mathrm{~A}$ based nanocomposites) show higher rheological properties compared to the samples prepared through one step mixing. This can be due to the localization of nanoclays in the PLA matrix. Biodegradability results showed that the hydroxyl groups of stacked and intercalated silicate layers which are dispersed in the PLA matrix can initiate heterogeneous hydrolysis of the PLA matrix after absorbing water from the compost. Comparison of the effects of $30 \mathrm{~B}$ and $15 \mathrm{~A}$ on the rate of biodegradation, based on somewhat different hydrophilicity, different kinds of modifier and slight filler dispersion differences, can explain the slightly lower rate constants observed for the 15A based nanocomposites. This investigation revealed that the mixing methods and localization of nanoclays has a signifi- 
cant effect on the morphology and rate of biodegradation. The main target of this study is to achieve a good morphology which leads to a good properties, processability and PLA degradability at moderate cost.

\section{References}

[1] Okamoto K., Toshima K., Matsumura S.: Degradation of poly(lactic acid) into repolymerizable oligomer using montmorillonite K10 for chemical recycling. Macromolecular Bioscience, 5, 813-820 (2005). DOI: 10.1002/mabi.200500086

[2] Chang J-H., An Y. U., Sur G. S.: Poly(lactic acid) nanocomposites with various organoclays. I. Thermomechanical properties, morphology, and gas permeability. Journal of Polymer Science Part B: Polymer Physics, 41, 94-103 (2003). DOI: $10.1002 /$ polb.10349

[3] Ray S. S., Okamoto M.: Polymer/layered silicate nanocomposites: A review from preparation to processing. Progress in Polymer Science, 28, 1539-1641 (2003). DOI: $10.1016 /$ j.progpolymsci.2003.08.002

[4] Oyama H. T.: Super-tough poly(lactic acid) materials: Reactive blending with ethylene copolymer. Polymer, 50, 747-751 (2009).

DOI: 10.1016/j.polymer.2008.12.025

[5] Pavlidou S., Papaspyrides C. D.: A review on polymer-layered silicate nanocomposites. Progress in Polymer Science, 33, 1119-1198 (2008).

DOI: 10.1016/j.progpolymsci.2008.07.008

[6] Ray S. S., Okamoto M.: Biodegradable polylactide and its nanocomposites: Opening a new dimension for plastics and composites. Macromolecular Rapid Communications, 24, 815-840 (2003).

DOI: $10.1002 /$ marc. 200300008

[7] Reeve M. S., MaCarthy S. P., Downey M. J., Gross R. A.: Polylactide stereochemistry: Effect on enzymatic degradability. Macromolecules, 27, 825-831 (1994). DOI: $10.1021 / \mathrm{ma} 00081 \mathrm{a} 030$

[8] Iwata T., Doi Y.: Morphology and enzymatic degradation of poly(L-lactic acid) single crystals. Macromolecules, 31, 2461-72467 (1998).

DOI: $10.1021 / \mathrm{ma} 980008 \mathrm{~h}$

[9] Hakkarainene M., Karlsson S., Albertsson A. C.: Rapid (bio)degradation of polylactide by mixed culture of compost microorganisms - Low molecular weight products and matrix changes. Polymer, 41, 2331-2338 (2000).

DOI: 10.1016/S0032-3861(99)00393-6

[10] Singh G., Kaur N., Bhuida H., Bajpai P. K., Mandal U. K.: Degradation behaviors of linear low-density polyethylene and poly(L-lactic acid) blends. Journal of Applied Polymer Science, 124, 1993-1998 (2012). DOI: $\underline{10.1002 / a p p .35216}$
[11] Singh G., Bhunia H., Rajor A., Choudhary V.: Thermal properties and degradation characteristics of polylactide, linear low density polyethylene, and their blends. Polymer Bulletin, 66, 939-953 (2011). DOI: $10.1007 / \mathrm{s} 00289-010-0367-\mathrm{x}$

[12] Raghavan D., Emekalam A.: Characterization of starch/ polyethylene and starch/polyethylene/poly(lactic acid) composites. Polymer Degradation and Stability, 72, 509-517 (2001). DOI: 10.1016/S0141-3910(01)00054-4

[13] Anderson K. S., Lim S. H., Hillmyer M. A.: Toughening of polylactide by melt blending with linear lowdensity polyethylene. Journal of Applied Polymer Science, 89, 3757-3768 (2003).

DOI: $10.1002 /$ app. 12462

[14] Kim Y. F., Choi C. N., Kim Y. D., Lee K. Y., Lee M. S.: Compatibilization of immiscible poly(L-lactide) and low density polyethylene blends. Fibers and Polymers, 5, 270-274 (2004). DOI: $10.1007 / \mathrm{BF} 02875524$

[15] Wang Y., Hillmyer M. A.: Polyethylene-poly(L-lactide) diblock copolymers: Synthesis and compatibilization of poly(L-lactide)/polyethylene blends. Journal of Polymer Science Part A: Polymer Chemistry, 39, 2755-2766 (2001).

DOI: $10.1002 /$ pola. 1254

[16] Rezgui F., G'Sell C., Dahoun A., Hiver J. M., Sadoun T.: Plastic deformation of low-density polyethylene reinforced with biodegradable polylactide, Part 1: Microstructural analysis and tensile behavior at constant true strain-rate. Polymer Engineering and Science, 5, 117-125 (2011). DOI: $10.1002 /$ pen.21797

[17] Rezgui F., G'Sell C., Dahoun A., Hiver J. M., Sadoun T.: Plastic deformation of low-density polyethylene reinforced with biodegradable polylactide, Part 2: Creep characterization and modeling. Polymer Engineering and Science, 5, 126-132 (2011). DOI: $10.1002 /$ pen. 21796

[18] Nuñez K., Rosales C., Perera R., Villarreal N., Pastor J. M.: Poly(lactic acid)/low-density polyethylene blends and its nanocomposites based on sepiolite. Polymer Engineering Science, 52, 988-1004 (2012). DOI: $10.1002 /$ pen.22168

[19] Fenouillot F., Cassagnau P., Majesté J-C.: Uneven distribution of nanoparticles in immiscible fluids: Morphology development in polymer blends. Polymer, 50, 1333-1350 (2009).

DOI: $10.1016 /$ j.polymer.2008.12.029

[20] Elias L., Fenouillot F., Majeste J. C., Cassagnau P.: Morphology and rheology of immiscible polymer blends filled with silica nanoparticles. Polymer, 48, 6029-6040 (2007).

DOI: $10.1016 /$ j.polymer.2007.07.061 
[21] Gubbels F., Blacher S., Vanlathem E., Jerome R., Deltour R., Brouers F., Teyssie Ph.: Design of electrical composites: Determining the role of the morphology on the electrical properties of carbon black filled polymer blends. Macromolecules, 28, 1559-1566 (1995). DOI: $10.1021 / \mathrm{ma} 00109 \mathrm{a} 030$

[22] Gubbels F., Jerome R., Vanlathen E., Deltour R., Blacher S., Brouers F.: Kinetic and thermodynamic control of the selective localization of carbon black at the interface of immiscible polymer blends. Chemistry of Materials, 10, 1227-1235 (1998).

DOI: $10.1021 / \mathrm{cm} 970594 \mathrm{~d}$

[23] Gubbels F., Jerome R., Teyssie P., Vanlathem E., Deltour R., Calderone A., Parente V., Bredas J. L.: Selective localization of carbon black in immiscible polymer blends: A useful tool to design electrical conductive composites. Macromolecules, 27, 1972-1974 (1994).

DOI: $10.1021 / \mathrm{ma} 00085 \mathrm{a} 049$

[24] Zaikin A. E., Zharinova E. A., Bikmullin R. S.: Specifics of localization of carbon black at the interface between polymeric phases. Polymer Science Series A, 49, 328-336 (2007).

DOI: 10.1134/S0965545X07030145

[25] Elias L., Fenouillot F., Majesté J-C., Martin G., Cassagnau P.: Migration of nanosilica particles in polymer blends. Journal of Polymer Science Part B: Polymer Physics, 46, 1976-1983 (2008). DOI: $10.1002 /$ polb.21534

[26] Wu D., Zhang Y., Zhang M., Yu W.: Selective localization of multiwalled carbon nanotubes in poly( $\varepsilon$-caprolactone)/polylactide blend. Biomacromolecules, 10, 417-424 (2009).

DOI: $10.1021 / \mathrm{bm} 801183 \mathrm{f}$

[27] Li Y., Shimizu H.: Novel morphologies of poly(phenylene oxide) (PPO)/polyamide 6 (PA6) blend nanocomposites. Polymer, 45, 7381-7388 (2004).

DOI: $10.1016 /$ j.polymer.2004.09.018

[28] Ray S. S., Bousmina M.: Effect of organic modification on the compatibilization efficiency of clay in an immiscible polymer blend. Macromolecular Rapid Communications, 26, 1639-1646 (2005).

DOI: $10.1002 /$ marc. 200500447

[29] A'shabi L., Jafari S. H., Khonakdar H. A., Baghaei B.: Morphological, rheological and thermal studies in melt processed compatibilized PA6/ABS/clay nanocomposites. Journal of Polymer Research, 18, 197205 (2011).

DOI: $10.1007 / \mathrm{s} 10965-010-9407-3$
[30] Kim H. B., Choi J. S., Lee C. H., Lim S. T., Jhon M. S., Choi H. J.: Polymer blend/organoclay nanocomposite with poly(ethylene oxide) and poly(methyl methacrylate). European Polymer Journal, 41, 679-685 (2005). DOI: 10.1016/j.eurpolymj.2004.10.042

[31] Durmus A., Kasgoz A., Macosko C. W.: Linear low density polyethylene (LLDPE)/clay nanocomposites. Part I: Structural characterization and quantifying clay dispersion by melt rheology. Polymer, 48, 4492-4502 (2007). DOI: 10.1016/j.polymer.2007.05.074

[32] Kale G., Kijchavengkul T., Auras R., Rubino M., Selke S. E., Singh S. P.: Compostability of bioplastic packaging materials: An overview. Macromolecular Bioscience, 7, 255-257 (2007).

DOI: $10.1002 / \mathrm{mabi} .200600168$

[33] Lunt J.: Large-scale production, properties and commercial applications of polylactic acid polymers. Polymer Degradation and Stability, 59, 145-152 (1998).

DOI: 10.1016/S0141-3910(97)00148-1

[34] Weir N. A., Buchanan F. J., Orr J. F., Farrar D. F., Dickson G. R.: Degradation of poly-L-lactide. Part 2: Increased temperature accelerated degradation. Journal of Engineering Medicine, 218, 321-330 (2004). DOI: $10.1243 / 0954411041932809$

[35] Ray S. S., Yamada K., Ogami A., Okamoto M., Ueda K.: New polylactide/layered silicate nanocomposite: Nanoscale control over multiple properties. Macromolecular Rapid Communication, 23, 943-947 (2002).

DOI: 10.1002/1521-3927(200211)23:16<943::AIDMARC943>3.0.CO;2-F

[36] Ray S. S., Yamada K., Okamoto M., Ogami A., Ueda K.: New polylactide/layered silicate nanocomposites. 3. High-performance biodegradable materials. Chemistry Materials, 15, 1456-1465 (2003).

DOI: $10.1021 / \mathrm{cm} 020953 \mathrm{r}$

[37] Maiti P., Batt C. A., Giannelis E.: Renewable plastics: Synthesis and properties of PHB nanocomposites. Polymeric Materials Science and Engineering, 88, 5859 (2003).

[38] He H., Lee L. J.: Poly(lactic-co-glycolic acid) and functional hydrogels for drug delivery applications. ANTEC Conference Proceedings, 3, 3356-3360 (2004).

[39] Zhou Q., Xanthos M.: Nanoclay and crystallinity effects on the hydrolytic degradation of polylactides. Polymer Degradation and Stability, 93, 1450-1459 (2008).

DOI: 10.1016/j.polymdegradstab.2008.05.014 